\title{
Differences in lipoxygenase activity as related to cultivar differences in superficial scald of apples
}

Judith Lynne Hercules Reynolds

West Virginia University

Follow this and additional works at: https://researchrepository.wvu.edu/etd

\section{Recommended Citation}

Reynolds, Judith Lynne Hercules, "Differences in lipoxygenase activity as related to cultivar differences in superficial scald of apples" (1999). Graduate Theses, Dissertations, and Problem Reports. 1039.

https://researchrepository.wvu.edu/etd/1039

This Dissertation is protected by copyright and/or related rights. It has been brought to you by the The Research Repository @ WVU with permission from the rights-holder(s). You are free to use this Dissertation in any way that is permitted by the copyright and related rights legislation that applies to your use. For other uses you must obtain permission from the rights-holder(s) directly, unless additional rights are indicated by a Creative Commons license in the record and/ or on the work itself. This Dissertation has been accepted for inclusion in WVU Graduate Theses, Dissertations, and Problem Reports collection by an authorized administrator of The Research Repository @ WVU.

For more information, please contact researchrepository@mail.wvu.edu. 
Differences in Lipoxygenase Activity as Related to

Cultivar Differences in Superficial Scald of Apples

\author{
Judith L. Hercules
}

Dissertation Submitted to the

Faculty of the Genetics and Developmental Biology Program

And

College of Agriculture, Forestry And Consumer Sciences

At West Virginia University

In Partial Fulfillment of the Requirement

For the Degree of

Doctor of Philosophy

In

Genetics/Biochemistry

Walter Kaczmarczyk, Ph.D., Chair

Rajeev Arora, Ph.D.

Keith Garbutt, Ph.D.

Laura Gibson, Ph.D.

Daniel Panaccione, Ph.D.

William Bryan, Ph.D.

Department of Plant and Soil Sciences

Morgantown, West Virginia

1999

Keywords: Apple, Lipoxygenase, Superficial Scald, Correlation, Cultivar Difference 


\section{ABSTRACT \\ Differences in Lipoxygenase Activity as Related to Cultivar Differences in Superficial Scald of Apples}

Judith L. Hercules

The relationship between lipoxygenase activity (LOX) and superficial scald was studied in the four apple cultivars (Malus domesticus Borkh.), Granny Smith (GS), Red Delicious (RD), Golden Delicious (GD) and York (YK) to determine if LOX is the genetic source of superficial scald or a means of predicting \% scalded fruit. For 1993, three harvests (five trees each) for GS and four harvests (five trees each) for RD, GD and YK of one bushel box each were picked at one week intervals. For 1994, there were three harvests (five trees each) for GS, RD and GD and four harvests (three trees each) for YK. LOX activity was determined on apple peel homogenates. Superficial scald evaluations were made visually after fruit was stored for 150 days in refrigerated storage $(4 \mathrm{C})$ plus seven days at room temperature $(20 \mathrm{C})$. There were significant cultivar differences in LOX and in scald for both years. Correlations between $\%$ scalded fruit and LOX were significant for the combined cultivars for both years but not significant for each cultivar each year. All correlations were low. More than 50\% of the variances in \% scalded fruit and LOX for both years were due to cultivar. LOX is an enzyme in the biosynthetic pathway leading to scald but is not the primary cause of scald. An economically useful LOX activity scale might be developed to predict $\%$ scalded fruit in cultivars or in market lots of fruit. 


\section{ACKNOWLEDGMENTS}

I sincerely thank my advisor, Dr. Walter Kaczmarczyk, for his instruction, guidance and especially for his patience throughout my graduate training. I also thank my graduate committee, Dr. Rajeev Arora, Dr. William Bryan, Dr. Laura Gibson, Dr. Keith Garbutt and Dr. Daniel Panaccione for their suggestions, guidance and assistance.

I thank Dr. Morris Ingle for the opportunity to conduct the research project with him. I also thank Dr. Edwin Townsend for his assistance with the statistical analysis and Kathy Fletcher for computer instruction and assistance.

Most especially, I thank my daughter, Elizabeth, my son-in-law, Kenneth Kissner, and my parents, George and Katherine, for their encouragement and both emotional and financial support and thanks, also, to my brother, Joseph, and my sister-in law, Shirley, and my niece, Shirley Jo, for their moral support and assistance through these many years of study. 


\section{TABLE OF CONTENTS}

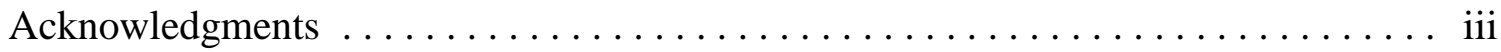

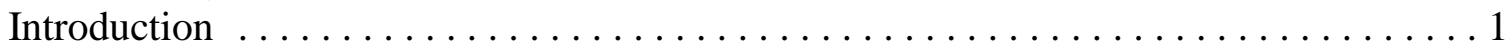

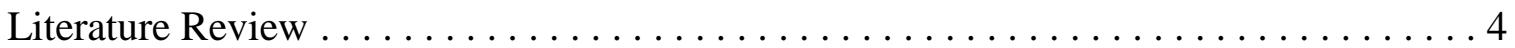

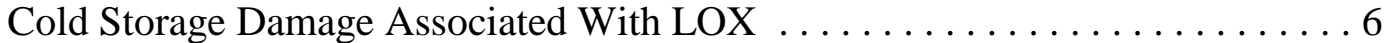

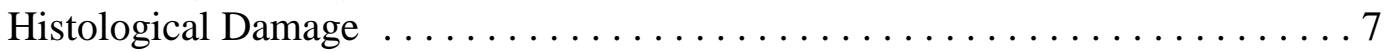

Respiration of Scalded Apple Tissue $\ldots \ldots \ldots \ldots \ldots \ldots \ldots \ldots \ldots \ldots$

Chemical Changes in Scalded Apple Tissues $\ldots \ldots \ldots \ldots \ldots \ldots \ldots$

Enzymatic Browning . . . . . . . . . . . . . . . . . . . . 10

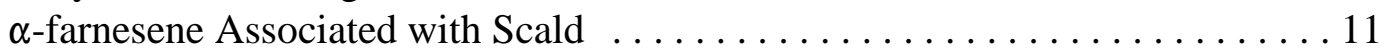

Lipid Peroxidation in Plant Tissues . . . . . . . . . . . . . . . . . . 12

Senescence and Lipid Catabolism . . . . . . . . . . . . . . . . . . 13

Triene Concentration in Scalded Fruit . . . . . . . . . . . . . . . . . . 14

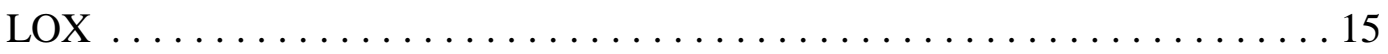

Presence and Formation of LOXs in Plant Tissues $\ldots \ldots \ldots \ldots \ldots \ldots \ldots \ldots$

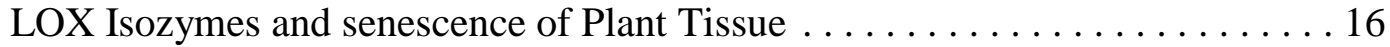

Tomato Fruit LOX . . . . . . . . . . . . . . . . . . . . 20

Associated with Microsomal membranes . . . . . . . . . . . . . 20

Purification and Partial Sequencing of TomloxA and TomloxB . . . . . . . . 22

Membrane-bound LOX from Apples . . . . . . . . . . . . . . . . . . . . 27

Changes in Principle Acids of Apples . . . . . . . . . . . . . . . 28

Factors Protecting $\alpha$-farnesene from Oxidation . . . . . . . . . . . . 29

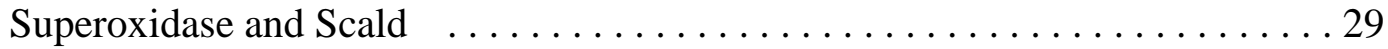

Effect of Warming Fruit After Refrigeration on Scald . . . . . . . . . . . . . 32

Concentration of Peroxidation Products and Scald Susceptibility . . . . . . . . 33

Linoleic Acid Pathway to $\alpha$-farnesene Production . . . . . . . . . . . . 35

Materials and Methods . . . . . . . . . . . . . . . . . . . . . . . . . 39

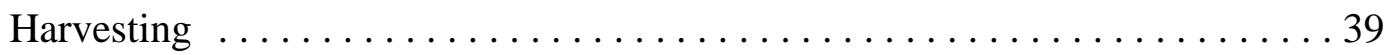

Apple Peel Homogenate . . . . . . . . . . . . . . . . . . . . . . 40

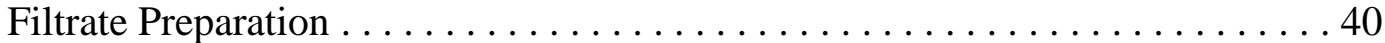

Protein Quantitation . . . . . . . . . . . . . . . . . . . . . . . 40

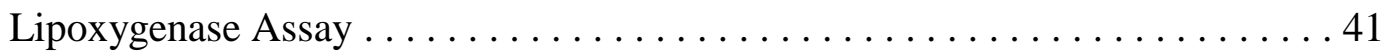

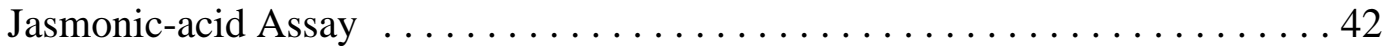

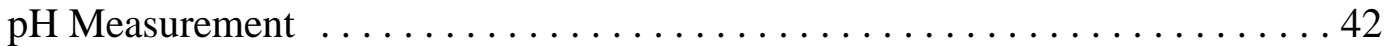

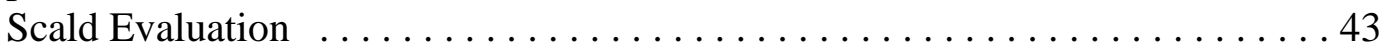

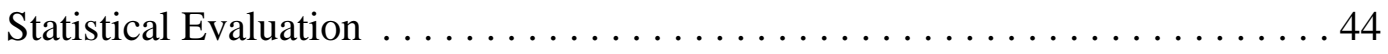

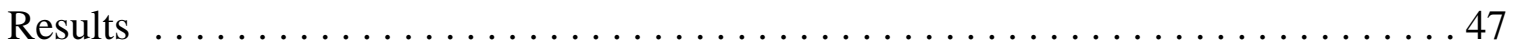

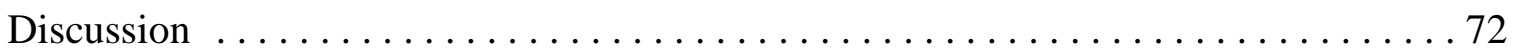

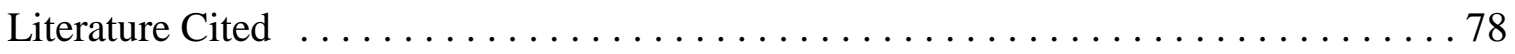

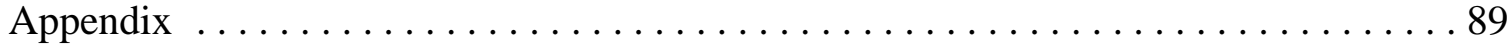

Coomassie Brilliant Blue . . . . . . . . . . . . . . . . . . . . 89 


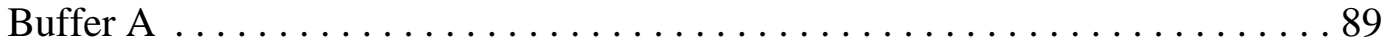

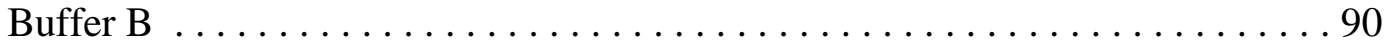

Linoleic Acid Substrate for LOX activity Evaluation $\ldots \ldots \ldots \ldots \ldots \ldots$ 


\section{LIST OF TABLES}

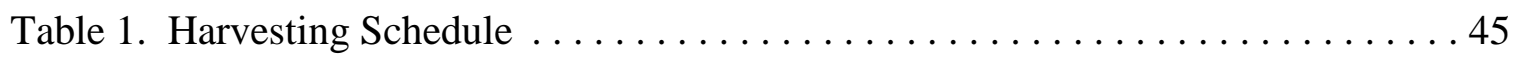

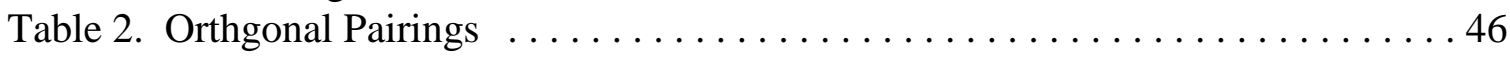

Table 3. Analysis of Variates for Lipoxygenase and $\%$ Scalded Fruit . . . . . . . . . 51

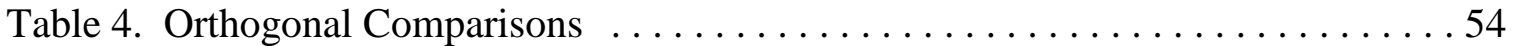

Table 5. Analysis of Variates for the Number of Apples of Each Scald Severity . . . . 55

Table 6. Correlations Between $\%$ Scalded Fruit and Lipoxygenase . . . . . . . . . 61

Table 7. Variances of \% Scalded Fruit and of Lipoxygenase Within Cultivars . . . . 71 


\section{LIST OF FIGURES}

Figure 1. Biosynthetic pathway from linoleic acid to jasmonate $\ldots \ldots \ldots \ldots \ldots \ldots 37$

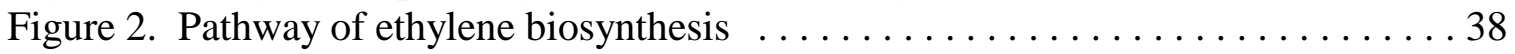

Figure 3. Comparison of 1993 harvest $\%$ scalded fruit $\ldots \ldots \ldots \ldots \ldots \ldots \ldots \ldots$

Figure 4. Comparison of 1994 harvest $\%$ scalded fruit . . . . . . . . . . . . . . . 53

Figure 5. Comparison of number of apples of each severity level for the 1993 harvest . 56

Figure 6. Comparison of number of apples of each severity level for the 1994 harvest 57

Figure 7. Comparison of LOX activity for $1993 \ldots \ldots \ldots \ldots \ldots \ldots \ldots \ldots$

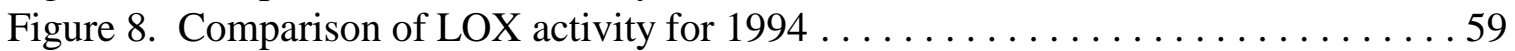

Figure 9. \% scalded fruit plotted against LOX for all 1993 cultivars . . . . . . . . 60

Figure 10. \% scalded fruit plotted against LOX for all 1994 cultivars . . . . . . . . . . 62

Figure 11. \% scalded fruit plotted against LOX for 1993 Granny Smith . . . . . . . . 63

Figure 12. \% scalded fruit plotted against LOX for 1993 Red Delicious . . . . . . . . . 64

Figure 13. \% scalded fruit plotted against LOX for 1993 Golden Delicious . . . . . . 65

Figure 14. \% scalded fruit plotted against LOX for 1993 York . . . . . . . . . . . 66

Figure 15. \% scalded fruit plotted against LOX for 1994 Granny Smith . . . . . . . . . 67

Figure 16. \% scalded fruit plotted against LOX for 1994 Red Delicious . . . . . . . . . 68

Figure 17. \% scalded fruit plotted against LOX for 1994 Golden Delicious . . . . . . . 69

Figure 18. \% scalded fruit plotted against LOX for 1994 York . . . . . . . . . . . 70

Figure 19. Lipoxygenase pathway to $\alpha$-farnesene $\ldots \ldots \ldots \ldots \ldots \ldots \ldots \ldots$ 


\section{INTRODUCTION}

The apple crop in the United States is approximately 3.9 million metric tons of fruit per year. A significant portion of this fruit is stored to prolong availability and to regulate market supplies (D'Souza, 1991). Due to increased restrictions by the United States government on the use of chemical scald inhibitors (D'Souza, 1991) a genetic source of scald control is being sought (Du and Bramlage, 1994a; Shewfelt and Pervis, 1995).

Superficial scald (scald) is a postharvest physiological disorder of apples. It is caused by the progressive browning of the dermal cells and is characterized by brown patches that develop in the skin during storage (Bain, 1956; Huelin and Coggiola, 1968; Ingle and D'Souza, 1989). The damage to apples produced by scald is superficial and usually does not affect the edible part of the fruit. However, scald is a grade defect that affects marketability. United States standards for grades of apples (U. S. Dept. Of Agr., 1972) specify that fruit classified as U.S. Extra fancy, U.S. Fancy and U.S. No. 1 be free from defects including scald. Not more than $10 \%$ of the apples in any lot may fail to meet the requirements of the grade with respect to scald provided that there are no other defects. Scalded apples can only be used for processing and their value is reduced (D'Souza, 1991).

Scald is only seen on apples after several weeks of refrigerated (4-5 C) and / or controlled atmosphere storage. It is more severe on fruit that have been taken out of storage and held at a higher temperature (e. g., 25 C) for several days (D’Souza, 1991). Cultivars differ in their susceptibility to scald. Also, maturity of the apples at the time of harvest influences the development of scald during storage (Anet, 1972: Ingle and D’Souza, 1989). Immature apples scald more rapidly 
than mature apples. Low oxygen storage and the use of the antioxidants diphenylamine (DPA) and ethoxyquin (EQ) are efficient scald inhibitors (Ingle and D’Souza, 1989). Both DPA and EQ are reevaluated periodically by the United States Department of Agriculture and withdrawal of one or both compounds for use as scald inhibitors is possible. Despite eight decades of research no causative factor has been correlated with scald potential in storage. If the degree of scald severity could be predicted, storage operators could eliminate or reduce the amount of chemical scald inhibitors, rather than applying the highest label rate, which is the usual practice. Therefore, nonchemical methods of scald control should be investigated (D'Souza, 1991).

The severity of scald is proportional to the amount of $\alpha$-farnesene in the skin of affected apples. Scald does not occur if oxidation of $\alpha$-farnesene is prevented or limited (Huelin and Coggiola, 1968; Anet, 1970; Ingle and D'Souza,1989). $\alpha$-farnesene is oxidized to conjugated triene (CT) products and the severity of scald is positively correlated with the degree of CT oxidation (Anet, 1969; Fobel, 1987). In addition to $\alpha$-farnesene, lipoxygenase (LOX) may be involved in the induction of scald (Ingle and D'Souza, 1989). There is evidence that the conversion of 1-aminocyclo-propane-1-carboxylic acid (ACC) to ethylene may be attributed to hydroperoxides generated by LOXs in senescing carnation flowers (Lynch et al., 1985) and increased ethylene production is associated with increased $\alpha$-farnesene production (Watkins $\underline{\text { et }} \underline{\text { al., }}$, 1993).

LOXs are commonly found in plant tissues. These enzymes catalyze peroxidation of polyunsaturated fatty acids to a variety of primary and secondary oxidation products. The principle substrates for LOXs in higher plants are linoleic and linolenic acid. LOX is thought to be important in the formation of flavors of many fruits and vegetables. LOX is involved in the synthesis of jasmonic acid which is a promoter of plant cell senescence (Hildebrand, 1989). LOXs have been 
implicated in flavor development and / or senescence in a variety of plant materials (apple (Feys, 1980 ; Ingle and D’Souza, 1989); cucumber (Wardale and Lambert, 1980); flowers (Fobel et. al., 1987, Lynch et. al., 1985, Peary and Prince, 1990); tomato (Todd et. al., 1990); and soybeans (Peterman and Siedow, 1985, Hildebrand, 1989).

The relationship between LOX and scald was studied in the four apple cultivars (Malus $\underline{X}$ Borkh.), Red Delicious (red, high scald susceptibility); York (red, low scald susceptibility); Granny Smith (non-red, high scald susceptibility); and Golden Delicious (non-red, low scald susceptibility). Red and non-red cultivar representatives of both high and low scald susceptibility were chosen to remove color bias from the study. 


\section{LITERATURE REVIEW}

The physiological disorder known as superficial scald, which results in browning of the skin

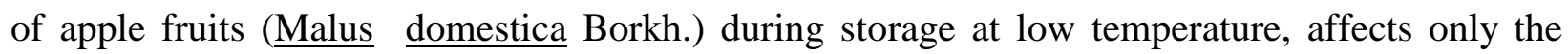
hypodermis tissue immediately beneath the epidermis of the fruit (Bain, 1956). The tissue browning only rarely extends into the flesh of the apple. Extent and the severity of scald development at low temperatures vary with the maturity of the fruit and with the length of time in storage. Immature fruits are very susceptible to scalding. Development of superficial scald in apples during or after storage at low temperature is due to the progressive browning of the contents of the cells of the hypodermis. When the disorder is slight, contents of the outer hypodermal cells are light brown while the inner adjacent cells appear to be normal. As the disorder becomes more severe, the browning of the skin deepens and the browning of the cells increases in intensity and extends through the five or six layers of the hypodermis. The epidermal cells are only affected (brown) in very severe cases. In severely scalded fruit, the affected cells of the hypodermis collapse in a radial direction so that the brown area becomes sunken. The outer cortex cells also become distorted but the shape of the epidermal cells is not affected. The affected cells often contained many chloroplasts but the chloroplasts were not disorganized (Bain, 1956). Storage temperature and warming experiments on Granny Smith apples provided evidence that superficial scald is a chilling injury (Watkins et $\underline{\text { al., }}$ 1995).

Chilling injury generally results from exposure of tropical or subtropical plants to temperatures below 10C to 15C (Watkins et al., 1995). However, temperate plants, which are resistant to chilling damage, are not immune to it. Chilling injury is viewed as a two-stage event, 
where rapid damage-inducing events are separated from symptom development events which involve cellular degeneration. Injury symptoms typical of superficial scald occurred after prolonged storage of Granny Smith at 0C or 4C, but not after storage at 10, 15 or $20 \mathrm{C}$ for times that produced generally equivalent changes in ground color. Interruption of $0 \mathrm{C}$ storage with a single warming period of 3 to 5 days at 10,15 or $20 \mathrm{C}$ reduced scald development after 25 weeks of storage, with maximum scald reduction occurring when fruit were for 3 to 5 days at 20C after 1 to 4 weeks at $0 \mathrm{C}$. Amelioration of scald by warming declined as storage time at $0 \mathrm{C}$ before warming increased. At the start of the experiment and at regular intervals during storage, ethylene production and background color were measured. Ethylene was measured on internal gas drawn into a syringe through a hypodermic needle inserted into the core cavity and ethylene concentrations were measured by gas chromatography. Color was assessed by a color reflectance meter. Color changes were taken as indications of relative senescence of fruit during storage. Stimulation of ethylene production by warming to $20 \mathrm{C}$ for 7 days after different periods at $0 \mathrm{C}$ was different. After 2 weeks at $0 \mathrm{C}$, ethylene production was low but was increased 135-fold after warming for 5 days at 20C. After 4, 6, 8, 10 and 12 weeks at $0 \mathrm{C}$, initial rates of ethylene production were much higher, but they increased only 10 -fold during warming. Accumulation of $\alpha$-farnesene and conjugated triene, in proportion to ethylene production rates, were far greater at 0C than they were at 20C. Ethylene-stimulated ripening and metabolism in the cold (0C) might be different from that at higher temperatures. These processes in the cold might result in metabolic imbalances that can lead to cell damage, but at higher temperatures these processes might condition fruit tissues against cell damage. Warming may be an effective nonchemical scald control method for Granny Smith apples and may have commercial implications for fruit that are not stored under controlled atmosphere (Watkins et al., 1995). 
Coldshock sensitivity in Brewing yeast strains has also been demonstrated (Fargher and Smith, 1995). Under growth conditions yeasts attempt to maintain the same degree of cell membrane fluidity, usually by altering the ratio of saturated/unsaturated fatty acids and sterols or by altering fatty acid chain lengths. These changes in fatty acid chain lengths are necessary to insure minimal disruption to the physicochemical properties of the membrane and to the function of integral proteins and transport mechanisms. If the rate of cooling is faster than the rate at which the yeast can modify its cell membrane composition, then the membrane fatty acids/sterols undergo a phase transition from fluid to "gel" states. These fatty acids/sterols may then be fixed in a random, disorganized fashion and the integrity of the membrane is compromised to such an extent that it leaks. The subsequent loss of cell contents results in the most commonly described symptoms of coldshock sensitivity (Fargher and Smith, 1995).

\section{Cold Storage Damage Associated With LOX}

Core Browning in Apple Fruit

A study of lipoxygenase (LOX) (EC1.13.11.12) activity in crude extracts of apple tissue in core, flesh, and peel showed a breakdown of linoleic acid occurring at the same time as the browning of the core of the apple cultivar Schone van Boskoop (Feys, 1980). LOX activity rose markedly over storage time at 3.5C from the eighth week to the twenty-eighth week, with the peel showing higher activity than the core. Many enzymes exhibit greater activity during climacteric, mainly in the peel and in the core. Climacteric is a period in the ontogeny of certain fruits, during which a series of biochemical changes is initiated by the autocatalytic production of ethylene, marking the change from growth to senescence and involving an increase in respiration and leading to ripening (Rhodes, 1970). A temperature change from 3.5C to 20C increased the browning to $80 \%$ after two 
weeks. Enzyme activities were calculated from initial rates of $\mathrm{O}_{2}$ uptake as 0 . The specific activity of the core enzyme after 28 weeks storage at $3.5 \mathrm{C}$ was $0.083 \mu \mathrm{M} \mathrm{O}_{2} / \mathrm{min} / \mathrm{mg}$ protein and after an additional two weeks at $20 \mathrm{C}$ was $0.2 \mu \mathrm{M} \mathrm{O}_{2} / \mathrm{min} / \mathrm{mg}$ protein. LOX activity in the core and in the peel increased during storage. It is possible that the LOX oxidation of polyunsaturated fatty acids is involved in the mechanism of scald induction (Feys, 1980). After the 20th week, a slight browning of the core was perceptible during storage at 3.5C and increased after 30 weeks. Storage at room temperature $(20 \mathrm{C}$ ) for two weeks generated a 4-fold increase in the browning. The relatively high LOX activity in the core may be responsible for the typical core browning during storage. This kind of physiological disorder may result from the action of LOX on the polyunsaturated acids which destroys the integrity of the lipoprotein membrane structures. The resulting disorganization of the living cell might explain the browning reactions. It is possible that LOX oxidation of polyunsaturated acids is involved in the mechanism of scald induction (Feys, 1980).

Histological Damage

Sections from scalded apples were examined with an electron microscope (Meigh, 1970). Two distinct types of disorganization were identified. In one, most obvious in the early stages of the disorder, vesicles were formed in the chloroplasts and throughout the cytoplasm. These changes closely resembled those occurring in aging, non-scalded tissue. In the other type of disorganization, new electron-dense substances were formed, the protoplasts became "tanned" and collapsed. This latter type was considered characteristic of scald, and occurred at the same time. Electron-dense material, pitted in appearance, developed and increased in quantity in the vacuole and also became concentrated in the tonoplast as the severity of the disorder increased. An additional layer of 
material, solid in appearance, developed between the cell wall and the plasma lemma. In the final stages of the disorder the cytoplasm and vacuoles became increasingly electron-dense, losing their identity as the cells collapsed. These changes were consistent with the breakdown of the control mechanism of the polyphenol system in the cell and electron-dense materials were symptoms rather than the cause of scald. Similar changes were found to occur after apples were treated with chloroform or after freezing and thawing (Meigh, 1970).

Respiration of Scalded Apple Tissue

The respiration rates of the skin tissue of normal and scalded areas were studied to determine the effect of scald at different stages of development on the metabolism of the skin (Siegleman and Schomer, 1953). The respiration of the skin tissues were measured under aerobic and anaerobic conditions (in nitrogen gas), in the presence of potassium cyanide, on addition of boiled apple juice and pyruvate, and in an atmosphere of air withdrawn from a commercial apple storage. Respiration rates were measured using standard Warburg procedures. Values obtained indicate that scald affected all the systems similarly, as there was no evidence that any particular system was inactivated in scalded tissue. Rather, there was a general reduction in all respiratory pathways. There is a relation between the severity of scald and the reduction of skin respiration. The oxygen uptake values for incipient and severely scalded tissue suggest a progressive reduction in skin respiration as scald develops. The nature of the reduction in respiration by scald was of a quantitative rather than a qualitative nature indicating that a portion of the cells are no longer functional and presumably dead. The cells still functioning appear to have the same respiratory behavior as normal cells (Siegleman and Schomer, 1953).

Scald is known to reduce the respiration rate of apple skin cells, but this is probably an 
indication of the onset of death (Smock, 1961). There is also an increase in catecholase activity in brown-colored apple skins, but this finding does not explain the cause of the disease. No difference has been found between the polyphenol oxidase activity of scalded fruit and fruit that is not scalded. Ascorbic acid losses and other organic acid changes did not seem related to scald development. However, a high ratio of ascorbic acid to dehydroascorbic acid resulted in resistance to scald. It is possible that the first steps in the production of scald are initiated by an enzyme occurring in an inactive combined form in the chloroplasts. Ferricytochrome $\mathrm{C}$ oxidizes phenol or polyphenol, and the resulting oxidation products then secondarily inhibit respiration of the affected epidermis (Smock, 1961).

Chemical Changes in Scalded Apple Tissue

Little is known about the chemical changes that precede visible signs of scald (Meigh,1970). Scald susceptible varieties of apple accumulated more alcohol and acetaldehyde during storage than those resistant to scald, suggesting that anaerobiosis was occurring. In apples affected by scald, skin permeability to gases decreased more during storage than in unaffected apples. The respiration rate of scalded apple skin was found to be lower than that of healthy tissue. This does little more than confirm that scalded tissue is dead (Meigh, 1970).

Changes in pyruvic, oxaloacetic, and $\alpha$-oxoglutaric acids were studied in Cox's Orange Pippin stored under conditions chosen to cause low temperature breakdown (Wilkenson, 1970). The group of disorders known as low temperature injuries occur at temperatures above the freezing point of the tissues and do not involve the formation of ice. Some fruits, such as pears (yㅏrs $\underline{\text { communis }}$ L.), do not normally suffer from these disorders, but for most fruits there is a threshold temperature below which the fruit might be damaged, if subjected to prolonged exposure. The lower temperature 
limit at which fruits behave normally varies with the region of origin. Temperate fruits such as apples may tolerate from 0 to $4 \mathrm{C}$ whilst the tropical banana (Musa cavendishii L.) behaves abnormally at temperatures below about 12C. Subtropical fruits such as citrus, avocados and pineapples tend to have critical temperatures down to $8 \mathrm{C}$. In apples, low temperature injury usually appears as a browning in the cortical region, with streaks of darker brown in the vascular tissues. The area of a cut surface which is discolored varies from the barely visible to $100 \%$, but the flesh may be badly affected before the injury appears as a darkening of the skin. The apples may appear to be sound until they are cut for examination. The boundary between affected and sound tissue is diffuse, and the intensity of the browning may vary from season to season. The tissue remains moist and does not dry out as in some other forms of flesh breakdown. Low temperature breakdown was preceded by an accumulation of oxaloacetic acid. Both the oxaloacetic acid content and the subsequent intensity of low temperature breakdown can be considerably reduced by a short interim period at a higher temperature during the cold storage of the fruit. Oxidation of succinate is inhibi ted by oxaloacetic acid in small amounts, and this would result in interference in the Krebs cycle. Inhibition of succinic dehydrogenase should cause $\alpha$-oxoglutarate to accumulate, which did happen in unwarmed fruit (Wilkenson, 1970).

Enzymatic Browning

Portions of apples were heated in a closed container to about 55C for a few minutes and then exposed to air. Enzymatic browning occurred, the location and appearance of which gave the effect of low temperature breakdown. Presumably the enzymes had not been inactivated as they would have been at a higher temperature, but cell permeability seems to have been reduced, allowing the cell contents to intermix (as happens in a cut surface). It is possible that at low temperatures, cell 
permeability was reduced without inactivation of the enzymes resulting in browning characteristic of low temperature breakdown. The primary disturbance in low temperature injury may be physical rather than chemical. It may be due to an effect on viscosity or membrane permeability (Wilkenson, 1970).

$\alpha$ - farnesene Associated With Scald

The naturally occurring sesquiterpene $\alpha$-farnesene is present in the coating of Granny Smith, Croften, and Delicious apples (Huelin and Murry, 1966). This occurrence of $\alpha$-farnesene in this coating, which has triterpene acids (mainly ursolic and oleanolic) as major constituents, suggests a direct origin from a farnesyl or nerolidyl intermediate in the biosynthesis of these triterpene acids. More farnesene was found in earlier picked apples, which are more sensitive to scald, and more in the scald-sensitive Granny Smith than in the scald-resistant Crofton variety (Huelin and Murry, 1966).

During storage of apples at 1C the maximum concentration of $\alpha$-farnesene in the "coating" (mainly cuticle) and adjacent cells (peelings in study were $1 \mathrm{~mm}$ thick) increased to a maximum of $15 \%$ of the total lipid of the coating and then declined (Huelin and Coggiola, 1968a). Evidence is presented for a role of $\alpha$-farnesene in superficial scald. More $\alpha$-farnesene was found in earlier picked apples and more in the scald-sensitive Granny Smith then in the scald resistant Crofton variety. During storage $\alpha$-farnesene moved from the fruit to the oiled paper wraps until the wraps contained more than twice as much as the fruit. Treatment with diphenylamine reduced the production of $\alpha$-farnesene in later picked apples. Although the effects of variety, maturity at picking, and oiled paper wraps on the level of $\alpha$-farnesene in the fruit were similar in their effect on scald, there was no significant correlation. During storage most of the scald appeared after $\alpha$ - 
farnesene peaked and continued to increase while $\alpha$-farnesene decreased. It is probable that the production of $\alpha$-farnesene is only the first stage in the development of scald and that the oxidation products of $\alpha$-farnesene are the causal agents (Huelin and Coggiola, 1968a).

$\alpha$-Farnesene is oxidized to conjugated triene (CT) products and the severity of scald was positively correlated with the degree of CT oxidation (Huelin and Coggiola, 1968b). These results suggest that oxidation of $\alpha$-farnesene is the cause of scald and that the control of scald by diphenylamine is due to its antioxidant action. This is supported by the fact that ethoxyquin $(\Delta$ ethoxy-2,2,4-trimethyl-1,2,-dihydroquiniline), another inhibitor of scald, is also an antioxidant. The oxidation of $\alpha$-farnesene in the natural apple coating proceeds much more slowly than in a pure film of $\alpha$-farnesene. The occurrence of natural antioxidants in the apple coating is indicated. Superficial scald involves the collapse and discoloration of hypodermal cells. Injury to the cells may occur as a result of the following sequence. Secretion of $\alpha$-farnesene by the epidermis and hypodermis may be followed by oxidation. $\alpha$-farnesene is protected from oxidation while in the living cell. The products of oxidation may then cause injury either by entering the cells or by polymerizing to impermeable films which prevent gas exchange. The process would be accentuated if oxidation of $\alpha$-farnesene promoted simultaneous oxidation of the unsaturated fatty acids of the coating (Fobel,1987).

\section{Lipid Peroxidation in Plant Tissues}

Pear (Var. Bartlett) and banana (Var. Valery) fruit contain fluorescent products of lipid peroxidation that increase during natural or ethylene-induced ripening. Senescing leaves and cotyledons also accumulate fluorescent peroxidation products which are localized in membrane lipid layers. Fluorescent peroxidized lipids are a family of compounds with a characteristic Schiff base 
structure $(\mathrm{N}=\mathrm{C}-\mathrm{C}=\mathrm{C}-\mathrm{N})$ formed by the reaction of aldehydes from peroxidized lipids with free amino groups (Hudak et al., 1995). Schiff bases formed from malondialdehyde and amino compounds have characteristic fluorescence spectra that feature an excitation maximum at $\sim 360 \mathrm{~nm}$ and an emission maximum at $\sim 430 \mathrm{~nm}$. Fluorescent peroxidized lipids appear to be formed in membrane bilayers, and if they were to accumulate therein, they could be expected to disrupt membrane structural integrity. The accumulation of peroxidized lipids in senescing membranes may contribute to the loss of membrane function as tissues age. Evidence indicates that fluorescent peroxidized lipids are released from membranes by blebbing (pinching of surface protrusions) of lipid-protein particles from the membrane surface (Hudak et al.,1995).The data have been obtained from studies with senescing bean (Phaseolus vulgaris L.) cotyledons grown under etiolation conditions and senescing carnation (Deanthus caryophyllus L.) flower petals. These lipid-protein particles have been tentatively termed deteriosomes to denote their putative role in removing lipid and protein catabolites from membranes. Lipid and protein catabolism is a normal feature of membrane turnover, and any significant accumulation of catabolites in the bilayer could have a disruptive effect on the membrane structure (Hudak et al..,1995).

\section{Senescence and Lipid Catabolism}

Impairment of this blebbing process with advancing senescence appears to result in an accumulation of lipid catabolites in senescing membranes that causes bilayer destabilization and loss of membrane function. Formation of nonsedimentable lipid-protein particles is a two-step process involving phospholipid catabolism, which is enzymatically mediated and gives rise to bilayerdestabilizing lipid catabolites, followed by blebbing from the membrane surface (Hudak 를.

Microsomal membranes from carnation petals and from bean cotyledons both exhibit LOX 
activity that is inhibited by n-propyl gallate. n-Propyl gallate also inhibits the formation of fluorescent peroxidized lipids in microsomal membranes as well as blebbing of nonsedimentable lipid-protein particles. These observations collectively indicate that the LOX reaction facilitates the formation of nonsedimentable, soluble, lipid-protein particles, and that peroxidized lipids formed by the LOX reaction may be among the prompter molecules that engender blebbing. That the protein, phospholipid and free fatty acids of nonsedimentable lipid-protein particles decline essentially in parallel suggests that the decreases reflect a change in abundance of the particles rather than a change in their chemical composition. There is no significant change in the polypeptide profile of the lipidprotein particles during senescence despite the pronounced decline in total particle protein. These observations collectively indicate that the ability of membranes to release destabilizing molecular catabolites, including fluorescent peroxidized lipids, by blebbing decreases with advancing senescence (Hudak et al.,1995) This decrease may be due in part to the decrease in bulk lipid fluidity that is characteristic of membrane senescence (Fobel,1987). Impairment of this putative housekeeping mechanism with age could be expected to contribute to bilayer destabilization and loss

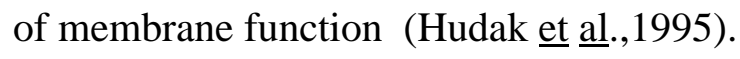

\section{Triene Concentration in Scalded Fruit}

Delicious apples (Starkrimson, Topred and Cascade) picked and evaluated at different times in 1990 consistently had higher triene concentrations in scalded peel compared to normal. In most cases it was a two to threefold difference (D'Souza,1991). Farnesene and antioxidant concentrations as in previous experiments were not significantly different between normal and scalded peel. Rome apples, like Delicious evaluated in 1990, contained significantly higher triene concentrations in scalded peel. Antioxidant and farnesene concentrations were not significantly different between 
normal and scalded peel. Scalded peel had significantly more triene than normal peel, but there were no significant differences between normal, senescent peel (breakdown) and peel that showed 'scald like' symptoms. In York apples it was determined that peel tissue with "York spot" had a higher triene concentration than normal tissue. Triene concentrations were also found to be significantly higher in bruised peel tissue of Granny Smith apples compared to unbruised peel tissue (D’Souza, 1991).

\section{LOX}

Presence and Formation of LOX's in Plant Tissues

Lipoxygenases which are commonly found in plant tissues, catalyze peroxidation of polyunsaturated fatty acids to various primary and secondary oxidation products. Multiple forms or isomers of LOX are often present. The principal substrates for LOX's in higher plants are linoleic (C18:2, omega6) and $\alpha$ - linolenic (C18:3, omega3) acids. These are the terminal fatty acids synthesized in most plant tissues. Linolenic acid is the most abundant fatty acid in most plant tissue and linoleic acid is often the most abundant fatty acid in plant seed. Linoleic acid is the precursor of other omega 6 fatty acids such as gamma-linolenic acid (6, 9, 12 all cis C18:3, omega6) and arachidonic acid (C20:4). $\alpha$-linolenic acid is the precursor of other omega 3 fatty acids such as eicosapentaenoic (C20:5) and decosahexaenoic (C:6) acids (all of which are substrates for LOX). LOX is important in the post harvest physioligy of many food products. Also LOX is thought to be important in the formation of flavors of many fruits and vegetables (Hildebrand, 1989).

In cucumbers, a sequence of lipid-degrading reactions is initiated by lipolytic and lipid oxidizing enzymes, including LOX. These enzymes produce the constituents that give cucumber 
flavor. LOX converts linoleic and linolenic acids to their hydroperoxide derivatives, which are then cleaved to form carbonyl fragments. LOX activity was higher in the peel than in the mesocarp and was associated with the vacuoles (Wardale and Lambert, 1980).

LOX Isozymes and Senescence of Plant Tissue

Soybean cotyledons are an excellent tissue for the study of senescence-related changes in LOX isozymes (LOX-1, LOX-2, LOX-3 and LOX-4) because they senesce on the plant within 24 days of planting and the senescence can be reversed by removal of the epicotyl followed by continuous pruning of axillary shoots. No LOX-1 isozyme activity was detectable by day 11 after planting. LOX-1 activity did not reappear in rejuvenated soybean cotyledons. Activity of LOX -2 and -3 dramatically decreased between day 7 and 11. LOX-2 and LOX-3 activity continued to decrease during senescence but at a much reduced rate. LOX -2 and -3 activity in rejuvenated cotyledons is more than 4-fold greater than the activity in 21-day old cotyledons, suggesting that LOX -2 and -3 may play a role in this metabolically active tissue. These results demonstrate that elevated LOX activity does not represent a universal characteristic of senescent plant tissue. LOX activity actually declines during senescence of soybean cotyledons attached to the plant (Peterman and Siedow, 1985).

The lipid fluidity of microsomal membranes from the petals of cut carnation flowers

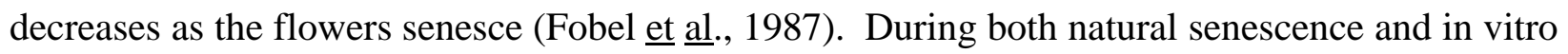
aging, there is a selective depletion of unsaturated fatty acids from the membranes. And there is a correlation between fluidity changes and the decrease in lipid unsaturation, and both are consistent with the contention that breakdown of membrane phospholipid generates fatty acid substrates for membranous LOX-like activity. Peroxidation of membrane lipids appears to be an inherent feature 
of senescence. The peroxidation reactions can be initiated enzymatically through LOX. A role for this enzyme in lipid peroxidation reactions of senescing membranes is suggested by the finding that some of the total LOX activity in senescing tissue is associated with membranes. In some tissues, LOX activity increases with advancing senescence in a temporal pattern that is consistent with its putative role in promoting oxidative damage. In other tissues LOX activity declines with age and this has been interpreted as being inconsistent with a putative role for LOX in the oxidative deterioration that preceeds cell death. This inconsistency may be partially due to the fact that the membrane associated enzyme, which is likely to be the most important form of the enzyme in terms of initiating peroxidative reactions within membrane bilayers, represents only a small proportion of total activity. Therefore, changes in total activity may not reflect changes in the activity of the membrane-associated form of the enzyme. Also, the timing and extent of peroxidative reactions initiated by LOX are likely to be determined more by the availability of endogenous substrate for the enzyme than by changes in its activity as measured in vitro in the presence of exogenous substrate. Thus, LOX in the membrane or in the cytosol will remain latent until substrate in the form of free fatty acid is released. LOX need only initiate lipid peroxidation which, once under way, is selfpropagating in the absence of inhibitors or scavenger. Therefore, accumulation of activated oxygen species with advancing senescence need not be dependent on increased LOX activity. During natural senescence, oleic acid rather than linoleic and linolenic acid was depleted from the total fatty acid pool (i.e. esterified and free combined), but within the fraction of free fatty acids, linoleic and linolenic acid were also depleted. The depletions of these fatty acids are consistent with the fact that only de-esterified linoleic and linoleic acids can be utilized as substrates by LOX. The large selective decline during natural senescence in oleic acid from the total fatty acid pool suggests that 
microsomal desaturases convert oleic acid into linolenic acid, thereby maintaining a pool of substrate for LOX. The role for LOX in initiation of perioxidation and the ensuing change in unsaturation is supported by the finding that the changes in fatty acid composition and lipid fluidity were inhibited by heat denaturation and were sensitive to $\mathrm{pH}$ (Fobel et al. , 1987).

During senescence of cut flowers, there is a progressive breakdown of phospholipids in the microsomal membrane and a corresponding rise in the membrane sterol: phospholipid ratio (Paliyath et al., 1987). Three phospholipid-degrading enzymes, phospholipase D, phosphatidic acid phosphatase, and lipolytic acyl hydrolase are present in the microsomal membranes of carnation ( Dianthus carophyllus L. Cv. White-sim ) flowers. The actions of these enzymes are responsible for the decline in microsomal phospholipid content during senescence. Four degradation products of the enzymes that mediate this phospholipid catabolism are choline and phosphatidic acid, which are formed by phospholipase $\mathrm{D}$; diacylglycerol, which could be a product of either phosphatidic acid phosphatase or phospholipase $\mathrm{C}$; and free fatty acids, which are formed through the activity of lipolytic acyl hydrolase. Choline and free fatty acids were found to increase with time. Lipolytic acyl hydrolase as measured by the release of free fatty acids showed a slight increase in activity at higher, non-physiological concentrations of free $\mathrm{Ca}^{2+}$ ( i.e. > 250 $\mu \mathrm{M}$ added $\mathrm{Ca}^{2+}$ ). The addition of calmodulin had no effect on the formation of free fatty acids. The breakdown of microsomal membrane phospholipids during senescence in cut carnation flowers and senescence-related membrane deterioration, including loss of phospholipid, can be accelerated by treating young flowers with exogenous ethylene. That the three phospholipid-degrading enzymes are intimately associated with the membranes is supported by the finding that they were not removed by washing the membrane preparation. Also, these enzymes are neither solubilized nor inactivated by treatment 
of the microsomal membranes with $0.38 \%$ (w/v ) Triton X-100. Two of the lipases associated with the microsome, phospholipase $\mathrm{D}$ and phosphatidic acid phosphatase, were stimulated by physiological concentrations of free $\mathrm{Ca}^{2+}$. Lipolytic acyl hydrolase was also slightly stimulated by $\mathrm{Ca}^{2+}$, but only at higher non-physiological concentrations. Phosphatidic acid phosphatase was more strongly stimulated by $\mathrm{Ca}^{2+}$ than phospholyase $\mathrm{D}$, and the $\mathrm{Ca}^{2+}$ stimulation of phosphatidic acid phosphatase appears to be mediated through the $\mathrm{Ca}^{2+}$-binding protein, calmodulen. Phosphatidic acid phosphatase in bean cotyledons has also been reported to be calmodulen dependent (Paliyath

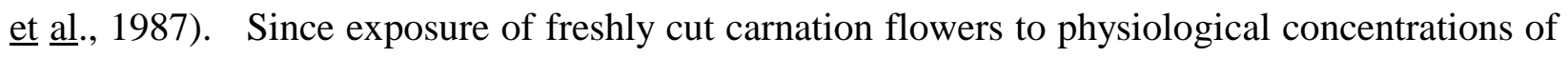
exogenous ethylene accelerates membrane senescence, the $\mathrm{Ca}^{2+}$ dependence of key lipid-degrading enzymes in the microsomal membranes raises the possibility that ethylene could be causing this effect through an agonist-dependent release of sequestered $\mathrm{Ca}^{2+}$ (Paliyath $\underline{\text { et }} \underline{\text { al., }}$ 1987).

In cut gladiolus (Gladiolus $x$ hortulanus Bailey cv. Manatee-white) petal tissue, the rise in LOX activity began when the flower was still unfurling and rose dramatically when the flower was fully opened but not showing any visible signs of senescence (Peary and Prince, 1990). The peak in activity coincided with early senescence. LOX activity in carnation (Dianthus caryophyllus L. cv. Improved White Sim) petal tissue was very low before opening of the flower but rose when the flower was fully opened with no visible signs of senescence. The peak in activity occurred with visible signs of early and mid-senescence. The peak of activity in carnation petals was about onetenth the peak for gladiolus petals. This increase in LOX activity, which was initiated before visible signs of senescence for both gladiolus and carnation, suggests that either LOX activity has a causal role in some degradative senescence processes or other early senescence processes only result in an increase in activity (Peary and Prince,1990). 


\section{Tomato Fruit LOX}

Associated With Microsomal Membranes

Microsomal membranes isolated from the pericarp of mature-green tomato fruit (Lycopersicon esculentum Mill.) rapidly metabolize exogenous radiolabeled linoleic acid into fatty acid oxidation products at 22C (Todd et al.,1990). The membranes also rapidly metabolize

radiolabeled L- $\alpha$-1-palmitoyl, 2-linoleoyl- $\left(1-{ }^{14} \mathrm{C}\right)$ phosphatidylcholine. When Triton X-100 treated membranes were used, the same patterns of metabolite formation were observed. Thus the enzymes mediating the breakdown of the radiolabeled compounds appear to be tightly associated with the membranes. The formation of fatty acid oxidation products is much lower at $30 \mathrm{C}$ than at $22 \mathrm{C}$ suggesting that LOX activity is considerably reduced at the higher temperature. The data indicate that there is a LOX associated with microsomal membranes from tomato fruit that utilizes free fatty acid substrate released from phospholipids. Fractionation studies designed to establish the subcellular localization(s) of LOX have proven problematic because soluble LOX tends to adhere nonspecifically to membranes. The microsomal LOX is strongly active over a $\mathrm{pH}$ range of 4.5 to 8.0, comprises $38 \%$ of the total (microsomal plus soluble) LOX activity in the tissue, and has an apparent Vmax, calculated from a Linewater-Burk plot with linoleic acid as substrate, of $186.3 \mu \mathrm{M}$ per minute per milligram of protein. The membranous enzyme cross-reacts with polyclonal antibodies raised against soybean LOX-1 and has an apparent molecular mass of $100 \mathrm{kD}$.

Given the strong preference of the microsomal LOX for free rather than esterified fatty acid substrate, the enzyme presumably remains essentially inactive until there is deesterification of phospholipid fatty acids. The membranous LOX may contribute to the loss of membrane function accompaning tomato fruit ripening and senescence since oxidized products of the LOX reaction are 
known to have deleterious effects on membranes and proteins. As ripening progresses and the membrane phospholipids are degraded, the resulting free fatty acids would be more readily available to the membrane-associated enzyme than the soluble enzyme (Todd et al., 1990).

Membrane-associated LOX from green tomato (Caruso) fruit was purified by solubilization of microsomal membranes with Triton-X-100, followed by anion-exchange and size-exclusion chromatography (Bowsher et al., 1992). The apparent molecular mass of the enzyme was estimated to be $97 \mathrm{kD}$ by sodium dodecyl sulphate-polyacrylamide gel electrophoresis (SDS PAGE) and 102 $\mathrm{kD}$ by size-exclusion chromatography. The purified membrane LOX preparation consisted of a single major band following sodium dodecyl sulfate-polyacrylamide gel electrophoresis, which cross-reacts with immunoserum raised against soluble soybean LOX-1. The membrane LOX has a pH optimum of 6.5, an apparent $\mathrm{Km}$ of $6.2 \mu \mathrm{M}$, and $\mathrm{Vmax}$ of $10.3 \mu \mathrm{M}$ per minute per milligram of protein with linoleic acid as substrate. These values for Vmax differ substantially from those reported for membrane-associated LOX by Todd et al. (1990) who reported corresponding values for the partially purified soluble LOX from tomato as Km of $0.52 \mu \mathrm{M}$ and Vmax of $186.3 \mu \mathrm{M}$ per min-1 per mg-1 of protein, respectively. There are two reasons for this discrepency: first, in Todd's study crude microsomal protein was used for the assay and second, an incorrect extinction coefficient was used for the diene product of the reaction. Therefore the membrane-associated enzyme was kinetically distinguishable from its soluble counterpart. Sucrose density gradient fractionation of the isolated membranes indicated that the membrane-associated LOX sediments in the same layer with thylakoids. A LOX band with a corresponding apparent molecular weight of $97 \mathrm{kD}$ was identified immunologically in SDS PAGE-resolved proteins of purified thylakoids prepared from

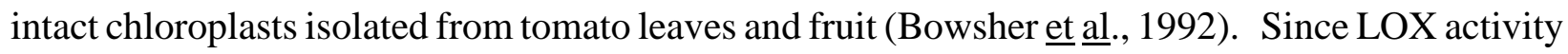


is highest in green breaker stage tomatoes, microsomal and cytosolic fractions from fruit at this stage of developement were used for protein purification. Results of initial experiments indicated that membrane-associated LOX activity was extremely unstable. Most LOX activity in the microsomal fraction isolated from the green fruit appears to be associated with thylakoid membranes. Identification of LOX protein in thylakoid membranes was confirmed immunologically. Thylakoids obtained from intact chloroplasts isolated from either tomato leaves or mature green fruit contain a protein at an apparent molecular weight of $97 \mathrm{kD}$ that cross-reacted with polyclonal antibodies raised against soybean LOX-1. Purification of the membrane-associated LOX gave a single major band of $97 \mathrm{kD}$ following SDS-PAGE. This band cross-reacted with soybean anti-LOX-1 antibody throughout the enzyme purification procedure. The similar apparent molecular weight of $192 \mathrm{kD}$ for the enzyme found when the molecular mass was measured by column chromatography supports the hypothesis that the functional unit of the enzyme is a single polypeptide monomer. These findings are in agreement with what has been found for other LOXs. The stability of the membrane LOX is extremely low, and purification had to be accomplished as rapidly as possible, because the enzyme lost activity even when stored at -20C. Because of this instability, increases in specific activity seen during the isolation protocol almost certainly underestimated the actual level of purification. In contrast, soluble LOX activity was quite stable at -20C, and did not decrease over a 3 month period. The membrane form appeared to be destabilized by removal from the membrane (Bowsher et al, 1992).

Purification and Partial Sequencing of TomloxA and TomloxB

A gene encoding a membrane-associated LOX from breaker-stage fruit of tomato was purified and partially sequenced (Ferrie et al., 1994). Two cDNA clones, tomloxA and tomloxB, 
were isolated and one of these (tomloxA) corresponded to the isolated enzyme. Genomic clones were isolated and sequence data from these were used to obtain the $5^{\prime}$ ends of the cDNAs. The 2.8-kb cDNAS encode proteins that are similar in size and sequence to each other and to other plant LOXs. Southern blot analysis indicated that tomato contains three or more genes that encode LOX. Northern blot analysis showed that tomloxA is expressed in germinating seeds as well as in ripening fruit, where it reached its peak during the breaker stage. TomloxB appears to be fruit specific and is at its highest level in ripe fruit.

The isolated enzyme was digested with endoproteinase and the resulting fragments were purified and sequenced. Amino acid sequences of the four resulting peptides were compared to pea, soybean, and tobacco LOX sequences. Three of the peptides showed high similarity to the legume (68-89\% identity) and tobacco sequences (78-100\% identity) sequences. The fourth peptide showed $94 \%$ identity with the tobacco sequence but no similarity to pea or soybean LOX. cDNA was synthesized and amplified from the RNA of breaker tomato fruit. A single band of around $830 \mathrm{bp}$ was produced and, based on known plant LOX sequences, a band of approximately 800 bp was expected. The DNA sequence of the 830 bp band showed 57 to $63 \%$ identity with the legume LOX sequence and the translation ends of the clone predicted amino acid sequences with $100 \%$ identity to the isolated peptides. This result indicated that this sequence was a partial cDNA for tomato LOX. A breaker-stage tomato pericarp cDNA library was constructed and screened with the $830 \mathrm{bp}$ PCR product. Of the three clones isolated, two were found to be identical after partial sequencing. The larger of the two $(1.8 \mathrm{~kb}$; which included the smaller clone sequence) and the third clone $(2 \mathrm{~kb})$ were fully sequenced. Both clones were found to be similar to other plant LOX genes, with overall nucleic acid sequence identity values of 60 to $70 \%$. The $1.8 \mathrm{~kb}$ clone was found to code for amino 
acids that corresponded exactly with sequence from the purified membrane-associated protein. This clone was designated tomlox A and the second clone was named tomloxB.

The 2860-nucleotide sequence of tomloxA consists of a 58-bp 5' untranslated region, a 2580bp open reading frame, a stop codon, and a 219-bp 3' untranslated region including an 18-bp poly(A) tail. The derived amino acid sequence has a predicted molecular mass of $96.8 \mathrm{kD}$. The amino acid sequences of the four purified peptides were found within this sequence. The 2759-nucleotide sequence of tomloxB consists of a 3' untranslated region of $162 \mathrm{bp}$ which includes a $15 \mathrm{bp}$ poly(A) tail and an open reading frame of $2577 \mathrm{bp}$ which predicts an 859-amino acid protein with a molecular mass of $97.1 \mathrm{kD}$. The amino acid sequence of tomloxB was found to differ at several residues from the purified peptides. Although the purified LOX was associated with thylakoid membranes, there was no evidence of a transit peptide sequence in either cDNA. At the DNA level the two tomato LOX genes show $74 \%$ homology, and at the amino acid level they show $72 \%$ identity. The amino acid sequences were compared to nine plant LOX sequences and a partial tobacco LOX amino acid sequence. Nucleic acid sequence homology values ranged from 54 to $65 \%$. At the amino acid level, identity values for tomloxA ranged from $56 \%$ with rice to $81 \%$ with tobacco. Values were similar but slightly lower (by 1-3\%) for tomloxB and the other plant LOX sequences except for the tobacco sequences, with which it shared $72 \%$ identity. There was little difference with either tomato LOX sequence compared to the various LOX sequences of soybean or pea.

The sequences of $\mathrm{N}$ termini of LOX genes differ markedly. However, following the $\mathrm{N}$ terminal 7 to 20 residues, there is a 17 -amino acid region within the $\mathrm{N}$ termini that is highly conserved, with most substitutions being conservative.There are three important regions of sequence 
similarity in LOX. The C-terminal 8 amino acids are highly conserved (GIPNSISI for all the legumes and rice and GIPNSVSI for Arabidopsis and both tomato LOXs). Tobacco is an exception to this. All of the plant and mammalian LOX sequences share a highly conserved region of 38 amino acids. This region spans amino acids 516 to 553 in tomloxA and tomloxB. There are 13 completely conserved residues in this region that are also found in both tomato sequences. The five conserved histidines (His) were suggested as possible iron ligands. There is a sixth conserved His about 160 rsidues downstream in all sequences (712 in tomloxA, 711 in tomloxB). This His is situated in a region of about 13 residues that are highly conserved in plant LOXs and mammalian 5-LOXs. This region has been suggested as an iron binding site. Site specific mutations of the six His's in soybean lipoxygenase-1 showed that H499, H504, and H690 (H521, H526, H712 in tomloxA) were necessary for enzyme activity and iron binding. Recent crystallographic determinations revealed the threedimensional structure of soybean LOX-1 and suggested the importance of many of the conserved residues in iron binding and enzyme activity. Five ligands have been identified: H499, H504, H690, the C-terminal carboxylate group of I839, and N694. The latter residue is conserved in all of the plant sequences including tomloxA (N716) but is substituted for by His in tomloxB (H715) and some of the mammalian LOXs. This is assumed to be a functional substitution. The results of Southern hybridization suggest that tomato LOX is encoded by a family of at least three genes. Two of these genes can be associated with tomloxA and tomloxB cDNAs. In addition, a putative third gene highly related to tomlox B cDNA was detected. The presence of similar sequences that could putatively encode a fourth, less closely related gene is suggested. These results suggest that tomato LOX is encoded by a family of at least three genes (Ferrie et $\underline{\text { al.,.1994) }}$

Two full-length LOX cDNA clones from tomato have been isolated and sequenced. As 
evidenced by amino acid sequence data, one of these, tomloxA, encodes a LOX that was purified from breaker-stage fruit. This enzyme had been found to be associated with thylakoid membranes. The deduced amino acid sequences for the two genes are very similar (72\% identity) to each other and to other plant LOXs. Although the LOXs are most divergent at the $\mathrm{N}$ termini, tomloxA displays enough similarity to the others to indicate a lack of a chloroplast transit peptide. Analysis of the genomic clones confirmed the translation start codon for tomloxA, thus excluding the possibility of peptide sequence beginning farther upstream. Nuclear-encoded chloroplast proteins are thought to require a cleavable, N-terminal transit peptide for transport into the chloroplast. At least three exceptions have been published. There is a possibility that tomloxA protein is targeted to the chloroplast using information in the mature protein. The two tomato LOX genes display different expression patterns during growth and ripening. TomloxA is expressed in germinating seeds. In fruit, tomloxA is expressed most strongly in the breaker stage, whereas tomloxB mRNA is at its highest level in ripe fruit. TomloxB appears to be fruit specific, whereas tomloxA may have different functions in different tissues. The significance of these expression patterns is unknown (Ferrie et al.,1994). As mentioned, ripening and senescence involve the loss of membrane integrety, and it has been proposed that LOX is involved in this process (Hildebrand, 1989). Perhaps the product of tomloxA contribute to changes in membrane structure that allow changes in metabolite distribution during ripening and germination. The LOX isoform of tomloxB may be more specific to the degradative processes of fruit senescence. Another possible mechanism for the involvement of LOX in tomato ripening is its role in the biosynthesis of jasmonic acid. This growth regulator has been shown to play a role in senescence with exogenous applications. The fatty acid hydroperoxides that are the primary products of the LOX reaction and that can be damaging to membranes can be 
converted to less damaging products. The characteristic odor of tomato is in part due to the volatile aldehyde hexanol, which results from the cleavage of the 13-linoleic acid hydroperoxide. TomloxB may be more specifically involved in this reaction than tomlox A (Ferrie et al., 1994).

\section{Membrane-bound LOX From Apples}

A membrane-bound LOX was partially purified from Golden Delicious apples by differential centrifugation and gel chromatography (Kim and Grosch,1979). The enzyme was isolated by two centrifugation steps generally carried out for the separation of the microsomal fraction from other components of plant cells. After homogenization of the microsomal fraction, LOX was further purified by chromatography on a Sepharose CL 2B column. A fraction (designated the Sepharose fraction) with LOX activity was eluted with the void volume in the range of $40 \times 10^{6}$ d. From these results it may be concluded that the enzyme associated with membranes has a high molecular weight. The total LOX activity of the Sepharose fraction was higher than that of the $10^{4} \mathrm{~g}$ supernatant. The activity of the Sepharose fraction in the presence of the $10^{4} \mathrm{~g}$ supernatant of the apple homogenate was measured and the results indicated that about $25 \%$ of the partial purified LOX is inhibited by components of the apple. LOX activity of the Sepharose fraction was higher in the presence of a detergent. For $0.64 \mathrm{mM}$ linoleic acid a maximum activity was observed in the presence of $0.2 \mathrm{mu} / \mathrm{mlL}$ of Tween 20. The $\mathrm{pH}$ response curve showed an optimum at $\mathrm{pH}$ 6.0. At the $\mathrm{pH}$ of apple pulp (3.6), LOX activity was only $12 \%$ of maximum. The enzyme lost $50 \%$ activity in 5 minutes at $40 \mathrm{C}$ and was completely inactivated by treatment at 50C for 10 minutes. The frozen enzyme remained stable for 5 days at -20C, although about $30 \%$ loss of its activity is observed after thawing at 2-4C (Kim and Grosch, 1979).

The substrate specificity of the Sepharose fraction showed a specificity for linolenic acid as 
compared to linoleic acid. The monohydroperoxides resulting from the oxidation of linoleic acid by the partially purified enzyme were isolated and analyzed by high pressure liquid chromatography. The results indicated that the apple LOX predominately catalyzes the formation of 13-hydroperoxyoctadeca-9,11-dienoic acid. LOX activity of the Sepharose fraction was inhibited by presence of EDTA or cyanide, EDTA being more effective. Preincubation of the Sepharose fraction in the presence of either EDTA or cyanide but in the absence of the substrate yields considerably less inhibition. This difference suggests that the inhibition by EDTA and potassium cyanide is reversible. The inhibition experiments furthermore provide evidence that a metal ion is involved in the catalysis of lipid peroxidation (Kim and Grosch, 1979).

\section{Changes in Principal Acids of Apples}

Changes in the principal acids were monitored in the ethanol-soluble matter of apples (cv. Glockenapfel) during a 6-month period between the beginning of July, while the apples were still on the tree, and January, after storage at 4C. Samples were taken at three week intervals for a total of nine times. Malic acid, with concentrations between 0.4 and $1.0 \%$ ( $\mathrm{g} / 100 \mathrm{~g}$ fresh wieght ) was the principal acid, only traces of citric and succinic acid were observed. The acid concentration in fruit flesh declined during development, although an increase was observed just before harvest. The decrease can be attributed to a dilution effect caused by an increase in mass during the cell growth phase. After storage, increased respiration was also responsible for the decline since malic acid is the principle metabolic substrate together with the sugars. Because of the cultivar influence, but also because of factors such as the weather or the ratio of leaves to fruit, it is very difficult to compare the composition of different apples. The values determined in this study were consistent with the values

for other varieties presented by other authors. Measurements were carried out after harvest when the 


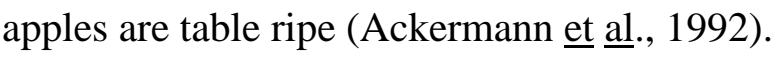

\section{Factors Protecting $\alpha$-farnesene From Oxidation}

Antioxidants are believed to protect against the oxidation of $\alpha$-farnesene to conjugated trienes in apple peel, thus providing resistance against superficial scald development (Barden and Bramlage,1994). Treatments studied were the number of accumulated hours at <10C, ripening (by application of ethephon), and exposure to light (assessed by enclosure in brown kraft bags). The data indicate that ripening substantially increased and bagging substantially decreased concentrations of $\alpha$-tocopherol, carotenoids, and ascorbic acid in apple peel. Increasing the number of hours at $<10 \mathrm{C}$ apparently also increased antioxidant concentrations, as indicated by estimates of total activity, but temperature affected antioxidents less than ripening and light. Changes in $\alpha$-tocopherol, carotenoids, and ascorbic acid were at least as great during ripening at $10 \mathrm{C}$ as during ripening at $<10 \mathrm{C}$. However, during this study, scald susceptibility was affected more by increasing hours at <10C than by ethephon-induced ripening or bagging. Therefore, the effects of low temperature in reducing scald susceptibility may involve some other factor than an increased concentration of the principle antioxidants in apple peel (Barden and Bramlage,1994).

\section{Superoxide Dismutase and Scald}

The superoxide radical is generated in all ripening cells, and can react with many cellular materials (Du and Bramlege, 1994a). It can lead to damage and losses in many foods. SOD is a ubiquitous defensive enzyme against superoxide damage to aerobic organisms. Three types of metalloenzymes of SOD exist in living organisms, namely CuZn-SOD, Fe-SOD, and Mn-SOD and all three SODs have been reported in higher plants. All three types of SOD catalyze the dismutation of superoxide anions to produce hydrogen peroxide in vivo. In apple fruit there is evidence of 
increased lipid peroxidation, including an increase in peroxidation products, peroxidation-induced membrane damage and LOX activity during senescence. Total superoxide dismutase (SOD:superoxide:superoxide oxidoreductase; E C 1.15.1.1) activity and individual activities of its three different metalloenzymes, CuZn-SOD, Fe-SO, and Mn-SO, were investigated during senescence of apples. Apples were from mature trees of three cultivars (Cortland, Empire, and Delicious) grown under standard horticultural conditions. Fruit were harvested at commercial maturity. Both superficial scald and senescent breakdown are senescence-related disorders that can occur during storage of apples. Activities of total SODs and CuZn- and Mn-SOD were much higher in peel tissue taken from areas above visible symptoms of senescent breakdown (soft, moist, darkened areas in the flesh) on Empire apples than in peel from healthy tissue. The increased SOD activities in senescent tissue may have been induced by tissue breakdown rather than by senescence or ripening, since senescing Empire fruit without symptoms of breakdown contained slowly declining activities of SODs during late storage. This was consistent with the finding that SOD activity remained at the same level preceding and during senescence of Golden Delicious apples. Scald development also involves collapse of cells and formation of dark lesions on the fruit surface. However, when peel from fruit with and without scald, and with different intensities of scald, were compared, no differences occured in any SOD form or total SOD activity. Thus, change in SOD activity with cell collapse seemed to be specific to the cause of collapse. Such differences in SOD activity among cultivars also seemed not to be correlated with succeptibility to superficial scald. Both Cortland and Delicious are scald susceptible but Empire is scald resistant. However, Empire contained SOD activity higher than Delicious but lower than Cortland (Du and Bramlage, 1994a).

During ripening on the tree, $\alpha$-farnesene conjugated triene (CT) measured at $258 \mathrm{~nm}$ (CT258), 
and CT measured at 281nm (CT281) increased greatly in peel of Cortland apples (Du and Bramlage, 1994a). These increases are referred to as rapid effects of ripening. This was in contrast to a delayed effect of ripening on $\alpha$-farnesene metabolism after fruit had been stored at $0 \mathrm{C}$ for 20 weeks, lateharvested (ripe) control fruit contained less $\alpha$-farnesene and CT281 but more CT258 and therefore a higher CT258/CT281 ratio than early harvested (unripe) control fruit. These data suggest that preharvest ripening accelerated the synthesis and oxidation of $\alpha$-farnesene with a relatively high proportion of oxidation products accumulating as CT281. However, when this fruit was stored at 0C for a prolonged time, it developed the capacity to accumulate substantially higher CT258 concentrations than early harvested fruit resulting in higher CT258/CT281 ratios for the late harvested fruit at removal from storage . CT258/CT281 ratios are associated with relatively low scald development, and ripening has long been known to reduce scald . CT281 and CT258 seem to be separate species or groups of species of $\alpha$-farnasene oxidation products, presumably both CTs. While CT281 seems to have a protective effect against scald development, since greater concentrations were associated with less scald development. The rapid effects of ethylene on scald development are viewed as ethylene-enhanced $\alpha$-farnesene synthesis and probably include more rapid flux of the entire sequence, with CT281 accumulation slightly favored over that of CT258, producing slightly reduced CT258/CT281 ratios . The delayed effects of ethylene are expressed as greater accumulation of CT258 than of CT281 late in storage. The rapid effects would favor scald development and the delayed effects would disfavor it. Whether scald symptoms developed on a fruit would be determined by the balance between the rapid and delayed effects of a particular condition. Ameliorization by delayed harvest may result from enhanced delayed effect of ripening, since the CT258/CT281 ratio after 20 weeks at 0C rose with later harvest. This ratio apparently had 
significance in individual fruit because fruit with increasing amounts of scald on them exhibited decreasing CT258/CT281 ratios. While effects from more advanced maturity often are confounded with those of greater exposure to low preharvest temperature, these results suggest that prestorage ripening alters $\alpha$-farnesene metabolism late in storage at $0 \mathrm{C}$, favoring accumulation of CT258 over that of CT281 and reducing the likelihood that scald lesions will form (Du and Bramlage, 1994a).

\section{Effect of Warming Fruit After Refrigeration on Scald}

An experiment on the effects of storage temperature, conditioning and warming on fruit provide clear evidence that superficial scald can be induced by chilling (Watkins,1995). Injury symptoms that are typical of scald occurred after prolonged storage of Granny Smith at 0 or 4C, but not after storage at 10,15 , or $20 \mathrm{C}$ for times that produced generally equavalent changes in ground color. Effects of warming the apples for different times ( 1 to 14 days at 20C) after 2 to 12 weeks at $0 \mathrm{C}$ is characteristic of fruit chilling injuries. Chilling injury is viewed as having two stages, where rapid damage inducing events are separated from symptom development events which involve cellular degeneration. Effects of warming meet this criterion since warming altered chemical

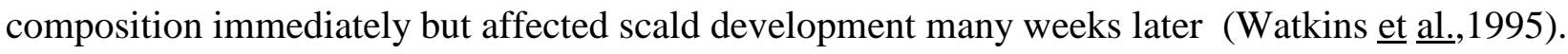

Warming reversed an effect of low temperature, but the scheduling of maximum effect of warming intervals had a different effect on 'Bramley's Seedling' from the effect on 'Granny Smith', so different cultivars may respond differently to warming regimes. According to the $\alpha$-farnesene hypothesis of scald development, treatments that inhibit scald should lower $\alpha$-farnesene production, inhibit $\alpha$-farnesene oxidation to CTs, or condition fruit tissues against injury by these products. Higher storage temperatures and warming treatments consistently raised $\alpha$-farnesene concentrations in fruit peel during treatment and at the end of storage, but reduced scald. This reinforced the view 
that $\alpha$-farnesene itself does not cause scald. $\alpha$-Farnesene accumulation may have been promoted by the high ethylene concentrations produced by fruit at higher temperatures. CTs also increased during warming. The CTs reported here, measured at $281 \mathrm{~nm}$, are the presumed scald-inducing species . Warming did not reduce scald unless fruit was first stored at $0 \mathrm{C}$. While the CTs increased during warming, they were lower at the end of storage (when scald was developing) in the warming treatments that produced the most scald reduction. Thus, warming may have induced events that gradually suppressed accumulation of scald-inducing CTs during long-term storage. However, as the storage time at $0 \mathrm{C}$ before warming increased the effect of warming on the induction of scald was reduced and CTs at the end of storage were not suppressed, indicating that CT accumulation could not be suppressed after extensive exposure to 0C (Watkins et $\underline{\text { al., }}$ 1995).

Rather than simply modifying $\alpha$-farnesene oxidation, warming may also have conditioned fruit tissue against damage from injurious products generated at low temperature. After two weeks at 0C, ethylene production was still low but it was stimulated 135 -fold during warming. At subsequent removals of fruit from storage $(4,6,8,10$, and 12 weeks at $0 \mathrm{C})$ initial rates of ethylene production were much higher, but they increased only 10 -fold during warming. $\alpha$-Farnesene and CT accumulations, in proportion to ethylene production rates, were far greater at $0 \mathrm{C}$ than they were at 20C. Conditioning fruit at 10C for up to 10 days before storage did not influence scald susceptibility, but during this time, no significant increase in internal ethylene concentration was observed. It was concluded that chilling induced superficial scald on Granny Smith apples (Watkins et al.., 1995).

\section{Concentration of Peroxidation Products and Scald Susceptibility}

Apple fruit (Cortland, Empire, and Delicious) was sampled under a variety of conditions related to scald development and assayed for some general peroxidation products, and for activities 
of enzymes that are important in controlling the accumulation of peroxidation products in plant tissues. Peroxidative characteristics in fruit peel of three apple cultivars were compared during storage at $0 \mathrm{C}$. Cortland and Delicious are scald susceptible, while Empire is scald resistant. The two groups of products of lipid peroxidation measured were the thiobarbituric acid-reactive substances (TBARS) and total peroxides (Du and Bramlage, 1995).

No general relationship existed between scald susceptibility and concentration of peroxidation products. Scald-resistant Empire apples contained higher TBARS and peroxide concentrations than scald-susceptible Cortland and Delicious. In addition, there was no difference in TBARS or peroxide concentrations in Cortland at scald-inducing and noninducing temperatures, and no sudden increase occurred as Cortland apples became liable to scald development on removal from storage. The increase in peroxidation products may have been associated with the increase of CT or with changes in cellular conditions that result in symptom development. The results provide no insight into events during scald symptom development. Tissue with different levels of symptom expression contained TBARS and peroxide concentrations equal to those in scald-free tissue and equal enzyme activities. Polyphenoloxidase (PPO) activity in peel was the same regardless of symptom development, cultivar and temperature. Only slight increases of PPO activity were found during fruit senescence (Du and Bramlage, 1995).

Peel over tissue with senescent breakdown had markedly different peroxidative characteristics than that from breakdown-free fruit. These results also suggest that development of scald symptoms is distinct from general cell breakdown and discoloration. No evidence was provided that marked changes in peroxidative activity of apple peel are related to scald development. Lipid peroxidation may be related to scald development in more subtle ways, especially in the susceptibility of cell 
membranes to perturbation by $\mathrm{CT}$, which may produce cellular disorganization and symptom expression (Du and Bramlage, 1995).

\section{Linoleic Acid Pathway to $\alpha$-farnesene Production}

Methyl jasmonate (MEJA) is synthesized via the peroxidation of linolenic acid by LOX (Fukuchi-Mizutani et al., 1995). Experiments with $\left[1-{ }^{14} \mathrm{C}\right]$-labeled linoleic acid showed that it was converted to linolenic acid to about $4 \%$ of the recovered radioactivity in the fatty acid phase of the in tomato cell culture and to $6 \%$ in tomato leaves after an incubation period of 24 hours (Gundlach and Zenk, 1998). The biosynthetic pathway for linolenic acid to jasmonic acid (JA) which includes 12-oxo-phytodienoic acid(12-oxo-PDA) has been confirmed and elucidated (see Figure 1; Gundlach and Zenk, 1998; Hamberg and Gardner, 1992; Sembdner and Parthier, 1993). In a screening program of 165 different plant cell cultures, a typical effect of 12-oxo-PDA was typically toxic and led to cell death in concentrations of 100-200 $\mu$ M. DH-12-oxo-PDA also induced cell death at $200 \mu \mathrm{M}$. MEJA rarely caused such toxic effects and only in concentrations of more than $500 \mu \mathrm{M}$ (Gundlach and Zenk, 1998).

Stimulating effects of MEJA on ethylene formation were found in ripening tomato and apple fruits. MEJA acts either by increasing the activities of either the 1-aminocyclopropane-1- carboxylic acid synthase or oxidase, apparently depending on plant species and developmental stage (see Figure

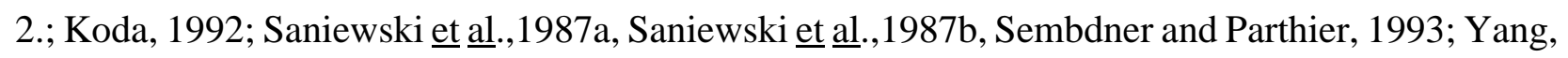
1987). JA increases ethylene forming enzyme (EFE) production resulting in increased ethylene formation (Koda,1992; Saniewski et al,1987b). Increased ethylene production has been associated with increased $\alpha$-farnesene production (Huelin and Murray, 1966; Mohr and Schopfer, 1995; Watkins et al., 1993). Ethylene seems to be critically involved in scald development, stimulating accumulation 
of $\alpha$-farnesene and CTs in fruit peel . Ethylene production or ripeness of fruit at the time they are placed in storage seems to affect the levels of CTs that accumulate in fruit peel late in storage (Du and Bramlage, 1994b).

LOXs are enzymes in the biosynthetic pathway that produces MEJA which stimulates the formation of ethylene. Ethylene has been shown to stimulate accumulation of $\alpha$-farnesene, which has been correlated with superficial scald severity. Therefore LOXs may be the enzymes responsible for development of superficial scald in apple fruit. 
Linolenic acid

13-hydroperoxy-octadecatrianoic acid (13(S)-HPOT)

12,13-epoxy-octadecatrienoic acid (EOT)

12-oxo-phytodienoic acid (12-oxo-PDA)

3-oxo-2-(2'-pentenyl)cyclopentaneoctanoic acid (OPC 8:0)

Linoleic acid

Lipoxygenase

Allene oxide

synthase

$\downarrow$

Allene oxide

cyclase

$\downarrow$

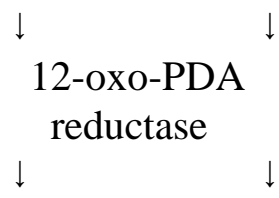

15,16-dihydro-12-oxo-phytodienoic acid (DH-12-oxo-PDA)
12,12-epoxy-octadecadienoic acid (EOD)

13- hydroperoxy-octadecdienoic acid (13(S)-HPOD)

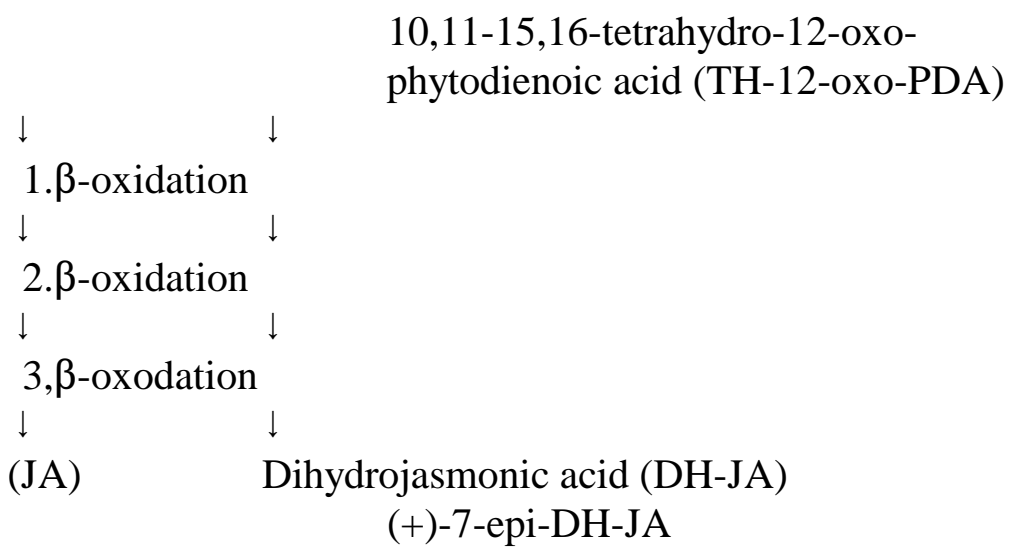

Figure 1. Postulated biosynthetic pathways for the linolenic and linoleic route to jasmonate and dihydrojasmonate, respectively (Gundlach and Zenk,1998). 


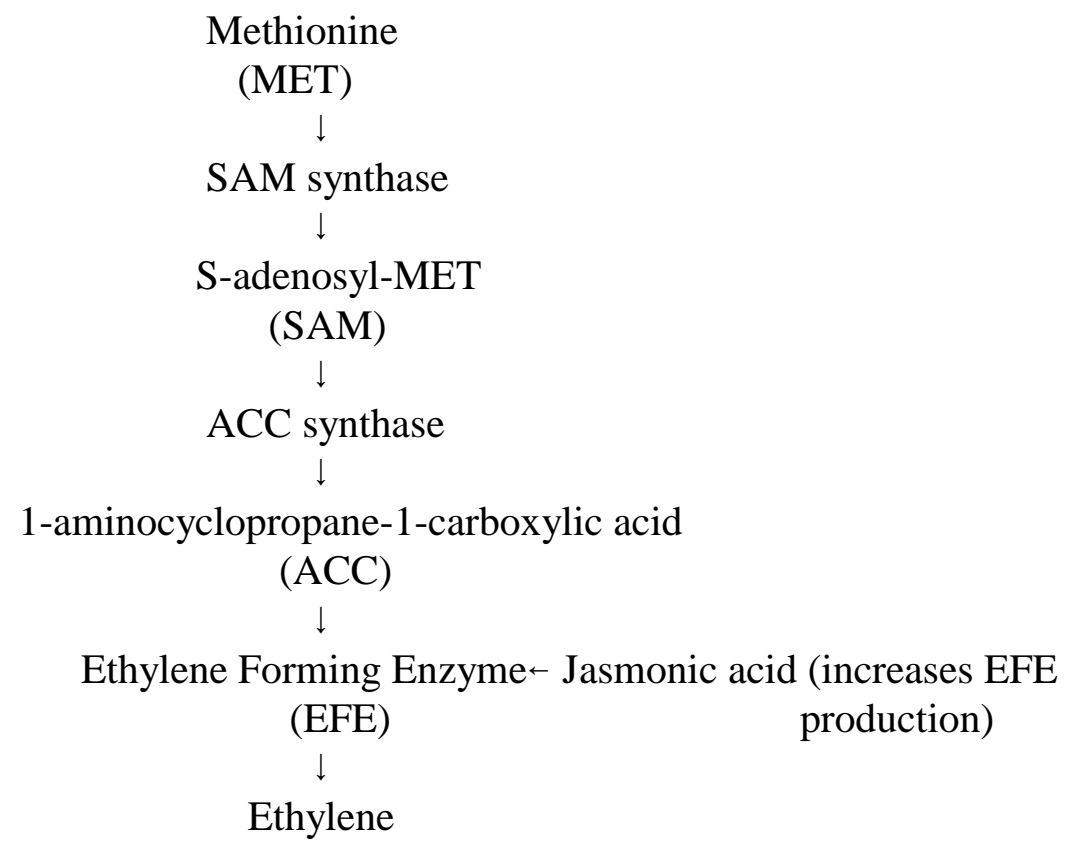

Figure 2. Pathway of ethylene biosynthesis (Yang, 1987). Jasmonic acid increases EFE production (Saniewski et al.,1987b; Koda, 1992). 


\section{MATERIALS and METHODS}

\section{Harvesting}

Four apple cultivars were selected for this study: Red Delicious, a red with high scald susceptibility; York, a red with low scald susceptibility; Granny Smith, a non-red with high scald susceptibility; and Golden Delicious, a non-red with low scald susceptibility. For each cultivar, fruit were harvested from either three or five trees planted with $6 \times 6 \mathrm{~m}$ spacing and were grown at the West Virginia University farm at Kearneysville, West Virginia. The soil at the Kearneysville Farm is Hagerstown silt loam (fine, mixed semiactive, mesic Typic Hapludalfs), which is a common orchard soil in West Virginia. Ground cover in the rows between the trees was tall fescue (Festuca arundenacea Schreb. Var Kentucky-31) .

The original sampling procedure called for two bushel boxes $(27-30 \mathrm{~kg})$ of fruit per tree to be taken at each of four harvest dates. The trees were assigned to the experiment by the staff at the Kearnysville farm and were not part of any other experiment. Fruit were hand picked at commercial maturity. The harvest dates were consistent with the number of days after full bloom (DAFB) harvest times used by commercial fruit producers (see Table 1.; Haller et al., 1950).

The apples were brought by truck to the Agriculture Sciences Building at West Virginia University at Morgantown and placed in $4 \mathrm{C}$ storage on the day of picking. Five unblemished apples were removed from each bushel box for protein and LOX assays within a week. Each apple was taken from a different area of the box. At each time apples were removed from the boxes for assay or for scald evaluation, bruised or rotten fruit was discarded. Scald evaluation was done on the sound fruit remaining after assay samples and rots were removed, therefore, the number of apples evaluated for scald varied. 


\section{Apple Peel Homogenate}

Filtrate Preparation

Five apples were placed in a wire mesh basket and rinsed with deionized distilled water for one minute. Each apple was dried with paper towels and peeled with a stainless steel household apple peeler. The entire apple was peeled and portions of the peel above damaged fruit flesh were discarded. Each peel was weighed as it was removed and immediately dropped into a polypropylene lidded freezer container containing $100 \mathrm{ml}$ of Buffer A (Appendix 1), combining the five peels into one sample per box. Additional Buffer A was added to give a ratio of $1 \mathrm{~g}$ of peel to $1 \mathrm{ml}$ of buffer. All buffer A was kept in an ice bath. The peel and buffer were placed in a Sorval Omni-mixer tissue homogenizer and pulsed at the \#5 setting for 20 seconds, seven times, with a 50 second cooling period between pulses. The homogenizer container was surrounded by crushed ice during the process. The homogenate was returned to the freezer container. About $10 \mathrm{ml}$ was placed in a 15 $\mathrm{ml}$ syringe and filtered through a Swinnex-25 millepore filter into a $15 \mathrm{ml}$ capped centrifuge tube. Both homogenate and filtrate were stored at -20 C immediately. Both protein concentration and lipoxygenase activity assays were run on the filtrate on the same day.

\section{Protein Quantitation}

The frozen apple peel homogenate filtrate from each replication (tree, represented by a box of fruit) was thawed by being placed at $4 \mathrm{C}$ for 18 hours to minimize loss of enzyme activity (Kim and Grosch, 1979). Filtrate tubes were kept on ice until aliquots were removed. Total protein concentration was determined by the Bradford Assay (Bradford, 1976). Protein was quantified to determine the amount of apple peel homogenate containing 75 to $100 \mu \mathrm{g}$ of protein as required for 
the lipoxygenase activity (LOX) determination (Todd et $\underline{\text { al., }}$ 1990; data not shown). A standard curve was prepared by preparing 10 to $100 \mu \mathrm{g}$ of bovine serum albumin in $0.1 \mathrm{ml}$ of $150 \mathrm{mM} \mathrm{NaCl}$. Next, $5 \mathrm{ml}$ of Coomassie Brilliant Blue reagent (Appendix 1) was added. The sample was vortexed and allowed to stand for 2 minutes at room temperature. Absorbency at $595 \mathrm{~nm}$ was determined using disposable cuvettes. All assays were run in duplicate on $10 \mu \mathrm{l}$ aliquots of sample and the results were averaged.

\section{Lipoxygenase Assay}

Lipoxygenase activity in the apple peel was measured spectrophotometrically (Todd, et al., 1990). Quartz cuvettes were used. The blank contained $3.5 \mathrm{ml}$ of Buffer B (Appendix 1).. Autostandardization was done with the reaction cuvette containing $2.5 \mathrm{ml}$ of Buffer B and $1.0 \mathrm{ml}$ of linoleic substrate (Appendix 1). For the apple peel filtrate assay, $2.5 \mathrm{ml}$ of Buffer B was placed in the reaction cuvette and a volume of the buffer equal to the filtrate aliquot volume was removed. The volume of filtrate used was calculated from the protein concentration to contain $75-100 \mu \mathrm{g}$ of protein. The cuvette was placed in the spectrophotometer, one $\mathrm{ml}$ of substrate was added to the cuvette, followed by addition of the aliquot of homogenate. The final volume in the cuvette was

$3.5 \mathrm{ml} . \Delta \mathrm{A}_{234}$ (change in absorbency at $234 \mathrm{~nm}$ ) after 120 seconds was recorded. One $\mathrm{A}_{234}$ unit was equavalent to the oxidation of $0.12 \mu$ mole of linoleic acid (Sigma, 1995).

$\Delta \mathrm{A}_{234}$ values were adjusted to $100 \mu \mathrm{g}$ of protein by the following equation;

$$
\Delta \mathrm{A}_{234} \mathrm{X} 100 \div \mu \mathrm{g} \text { protein in sample }=\Delta \mathrm{A}_{234} / 100 \mu \mathrm{g} \text { sample protein }
$$

The remainder of the sample was refrozen and stored at -20 C. 
Jasmonic Acid Assay

Apple peel filtrate was thawed to room temperature immediately before the evaluation. Two $\mathrm{ml}$ of apple peel filtrate were mixed with $3 \mathrm{ml}$ of ethyl acetate (Baker) in a polypropylene capped centrifuge tube. The mixture was vortexed for $30 \mathrm{sec}$. and centrifuged for one minute at $10,000 \mathrm{rpm}$ in an Eppendorf table top centrifuge. One $\mu 1$ of the upper (non-aqueous) layer was mixed with $1 \mu 1$ methylute (Pierce) in a 1 cc syringe (Pierce) and immediately injected into a Finigan MAT GS/EI-CI Mass Spectrometer System Varian Star 3420 Gas Chromatograph using a DB 1701 Capillary Column $30 \mathrm{~m}$ long with a diameter of $0.25 \mathrm{~mm}$. The temperature range was $50 \mathrm{C}$ to $300 \mathrm{C}$ at $15 \mathrm{C}$ per minute. The carrier gas was helium at $10 \mathrm{psi}$. The injection and transfer temperature was $260 \mathrm{C}$. The mass spectrophotometer was at 70 EV (Pierce,1989). Gas chromatogram-Mass Spectroscopy (GC/MS) evaluations were done by Robert Smith, GC/MS technician, Health Sciences, West Virginia University. Jasmonic Acid (Sigma) was used for the standard and showed peaks at $83 \%$, $151 \%$, and $224 \%$ Relative Intensity (Ueda and Kato, 1980).

\section{$\mathrm{pH}$ Measurements}

The $\mathrm{pH}$ of the filtrate was measured using a Markson Model $4603 \mathrm{pH}$ meter. One filtrate from each cultivar from each DAFB was measured. 


\section{Scald Evaluation}

Scald evaluation was done by evaluation of all sound fruit remaining from the original crate of apples after 150 days of storage at 4C and 7 days at 25C (Du and Bramlage, 1993; Barden and Bramlage, 1994; Du and Bramlage, 1994b; Du and Bramlage, 1995). Each apple was picked up and a visual estimate of the percent of the surface of the apple affected by scald was made according to the following scale;

$$
\begin{aligned}
& \mathrm{SA}=0 \% \\
& \mathrm{SB}=\text { up to } 10 \% \\
& \mathrm{SC}=11 \% \text { to } 50 \% \\
& \mathrm{SD}=\text { more than } 50 \%
\end{aligned}
$$

The \% scalded fruit was calculated by the following equation:

$$
(\mathrm{SB}+\mathrm{SC}+\mathrm{SD}) \div(\# \text { Apples evaluated }) \mathrm{X} 100=\% \text { Scalded fruit }
$$

The $\%$ scalded fruit in each category (SA, SB, SC or SD) was calculated by the following equation:

$$
\text { \#Apples/category } \div \text { \#Apples evaluated X } 100=\% \text { Apples/category }
$$




\section{Statistical Evaluation}

Simple one way analysis of variance with trees as replicates was used to determine differences between cultivars for LOX, \% scalded fruit and number of fruit showing each designation of scald severity using the General Linear Model (SAS, 1990). Pearson Partial Correlation coefficients between LOX activity at harvest and \% scalded fruit were determined holding tree and harvest date constant. The sums of squares for cultivars were partitioned into orthogonal comparisons for LOX and for \% scalded fruit (Table 2). The estimated mean squares for LOX and for $\%$ scalded fruit were decomposed to determine the $\%$ of the variances due to cultivar. Data from the two harvest years , 1993 and 1994, were analysed as two separate experiments since different groups of trees were studied each year. P-values $\leq 0.05$ were considered significant. 
Table 1. Harvesting schedule for Granny Smith (GS), Red Delicious (RD), Golden Delicious (GD) and York (YK) apple fruit for the 1993 and 1994 harvest seasons including the numbers of trees sampled for each Days after full Bloom (DAFB) ${ }^{\mathrm{X}}$ harvest event.

CULTIVAR NUMBER of TREES DAFB

1993

$\begin{array}{lll}\text { GS } & 5 & 167,174,181 \\ \text { RD } & 5 & 133,139,146,152 \\ \text { GD } & 5 & 133,139,146,152 \\ \text { YK } & 5 & 161,167,174,181\end{array}$

1994

GS 5

RD 5

GD 5

YK 3

$166,173,180$

$138,145,152$

$138,145,152$

$152,159,166,173$

${ }^{\mathrm{X}}$ Haller et al., 1950. 
Table 2. Orthogonal pairings for Granny Smith (GS), Red Delicious (RD), Golden Delicious (GD) and York (YK) cultivars.

Comparison 1: $\quad$ Scald susceptibility

$\begin{array}{ccc}\text { High } & \text { versus } & \text { Low } \\ \text { GS \&RD } & & \text { GD \& YK }\end{array}$

Comparison 2:

$\begin{array}{lll} & \text { Color } & \\ \text { Red } & \text { versus } & \text { Non-red } \\ \text { RD \& YK } & & \text { GS \& GD }\end{array}$

Comparison 3: $\quad$ Interaction

GS \& YK versus $\quad$ RD \& GD 


\section{$\underline{\text { RESULTS }}$}

Due to environmental conditions in 1993 and 1994 the harvesting schedule was changed. For 1993, there were only three harvest events for Granny Smith (GS). For 1994, there were only three harvest events each for GS, RD and GD (Table 1). Rainfall was low during the summer and the fall 1993 so that there were fewer and smaller apples than for a normal year. Two boxes per tree were taken from 133 Days After Full Bloom (DAFB) until 161 DAFB. These harvest times included all of the RD and GD harvests and the first YK harvests. From 167 DAFB through 181 DAFB only one box per tree was obtained. These harvest times included the last three YK and the GS harvests. All fruit was harvested by 181 DAFB so that there were only three GS harvests. Hail damage in 1994 produced surface blemishes on some of the crop that would bar the fruit from the test area from the fresh fruit market. One box per tree was obtained from each of five trees for GS, RD and GD. There were three harvests for each of these test cultivars. One box from each of three trees for four harvests were gathered for YK.

There was a significant cultivar difference in \% scalded fruit for both the 1993 $(\mathrm{P} \leq 0.0001)$ and the $1994(\mathrm{P} \leq 0.0001)$ harvest seasons (Figure 3, Figure 4 and Table 3). For 1993, the high scald susceptibility cultivars, GS (100\%) and RD (100\%), had significantly more scalded fruit $(\mathrm{P} \leq 0.0001)$ than the low scald susceptibility cultivars, GD $(58 \%)$ and $\mathrm{YK}(40 \%)$. The two nonred cultivars, GS and GD, had significantly more scalded fruit $(\mathrm{P} \leq 0.001)$ than the two red cultivars, $\mathrm{RD}$ and $\mathrm{YK}$. The interaction comparison was also highly significant $(\mathrm{P} \leq 0.001)$. GS and RD had the same $\%$ scalded fruit. This means that the difference between GD and YK was also highly significant. The results for 1994 were similar, with the exception that YK had more scalded fruit than GD (Table 4). 
For 1993, a comparison of the number of apples of each scald severity level (SA, SB, SC and SD) showed significant cultivar differences $(\mathrm{P} \leq 0.0001)$ (Table 5). GD and $\mathrm{YK}$ were predominately in the SA and SB categories with few or none in the SC and SD categories. GS and RD showed the reverse pattern of few or none SA and SB fruit and more in the SC and SD levels of scald (Figure $5)$.

The 1994 harvest season showed cultivar differences $(\mathrm{P} \leq 0.0001)$ (Table 5) in all four levels of severity of scald. GD and YK had more SA and SB fruit and fewer SC and SD. GS had few SA and SB fruit and higher numbers in the SC and SD categories. RD had more SB fruit than fruit at any other level (Figure 6).

There was a significant cultivar difference in LOX at harvest for the four test cultivars in 1993 ( $\mathrm{P} \leq 0.0001)$ (Figure 7 and Table 3$)$. GS and RD had significantly higher $\mathrm{LOX}(\mathrm{P} \leq 0.001)$ than GD and YK. The two red cultivars had significantly higher LOX $(P \leq 0.05)$ than the two non-red cultivars. The interaction comparison was also highly significant and since GD and YK had the same LOX activity this means that the difference between GS and RD in LOX activity was highly significant (Table 4). There was a cultivar difference in LOX at harvest for the 1994 harvest season $(\mathrm{P} \leq 0.01)$ (Figure 8 and Table 3$)$. The GS and RD LOX at harvest were significantly higher $(\mathrm{P} \leq$ $0.001)$ than those of GD and YK. The non-red cultivars had significantly higher $\operatorname{LOX}(\mathrm{P} \leq 0.05)$ than the red cultivars and the interaction comparison was not significant (Table 4).

For the 1993 harvest season $97.4 \%$ of the variance in $\%$ scalded fruit and $90.1 \%$ of the variance in LOX was due to cultivar. For the 1994 harvest season $94.9 \%$ of the variance in $\%$ scalded fruit and $52.9 \%$ of the variance in LOX was due to cultivar (Table 3).

The combined cultivar correlation between \% scalded fruit and LOX for the 1993 harvest 
year (0.6446) was highly significant $(\mathrm{P} \leq 0.0001)$ (Figure 9 and Table 6$)$ and for the 1994 harvest season the combined cultivar correlation 90.3992) was significant $(P \leq 0.01)$ (Figure 10 and Table 6). The 1993 observations show a pattern of \% scalded fruit increasing with increasing LOX. The 1994 observations show a more scattered pattern than the 1993 data with the low \% scalded fruit exhibiting low LOX and the high \% scalded fruit exhibiting high LOX (Figures 9 and 10). All of the 1993 GS \% scald values were the same and therefore correlation was not appropriate (Townsend, 1998) (Figure 11). The correlations between \% scalded fruit and LOX for RD, GD and YK for 1993 were not significant $(\mathrm{P} \geq 0.05)$ (Table 6). The $1993 \mathrm{RD}$ had a negative correlation (-0.1432). The two observations that had less than $100 \%$ scalded fruit had higher LOX than some of the $100 \%$ scalded fruit (Figure 12). Of the 1993 GD (0.0529), the lowest \% scalded fruit exhibited the lowest LOX and the highest \% scalded fruit had the highest LOX (Figure 13). The 1993 YK (0.1058) had the lowest \% scalded fruit with the lowest LOX (Figure 14). The other observations for 1993 GD and YK were not shown to be distributed equally about a curve (Figures 13 and 14).

The 1994 GS also had all \% scalded fruit values the same and correlations were not appropriate (Townsend, 1998) (Figure 15). The 1994 RD (0.0078) replicates all had over 60\% scalded fruit. The lowest LOX fruit had higher \% scald than the highest LOX (Figure 16). The 1994 GD (0.2333) had little variation in \% scalded fruit with some increase in \% scalded fruit with increasing LOX (Figure 17). The 1994 YK (0.4142) showed little variation in LOX but did have a pattern of higher \% scalded fruit associated with higher LOX (Figure 18).

The 1993 LOX variances of GS and RD were similar to each other but were about three times greater than GD and YK. GD and YK LOX variances were close. There was no variance in \% scalded fruit for GS in 1993. GD had about twice the variance as YK and both were about 100 times 
greater than RD (Table 7).

For 1994, the GS and RD LOX variances were close to each other and about three times the variance of GD and YK. GD and YK were similar to each other. There was no variance in GS replicates for \% scalded fruit in 1994. The variances for RD, GD and YK were similar (Table7).

The $\mathrm{pH}$ response curve for apple LOX shows optimum activity at 6.0 with $90 \%$ of activity occuring between pH 5.1-6.2 (Kim and Grosch, 1979). The apple peel homogenates from the test cultivars had a pH range of 5.0-6.8. Eighty-nine $\%$ of the homogenates were within the optimum $\mathrm{pH}$ range.

GC/MS showed the presence of three (and probably a fourth) positional isomers of jasmonic acid in Granny Smith but not in the other three cultivars. They were (1) cis, cis, (2) cis (probably the highest concentration), (3) not trans (low concentration), (4) not identified (probably the lowest concentration) (Smith, 1996). 
Table 3. Analysis of variates for lipoxygenase activity ${ }^{\mathrm{x}}$ (LOX)and for $\%$ scalded fruit for Granny Smith (GS), Red Delicious (RD), Golden Delicious (GD) and York (YK) apples for the 1993 and for the 1994 harvest seasons.

\begin{tabular}{|c|c|c|c|c|c|c|c|}
\hline Year & Source & df & $\begin{array}{l}\text { Sum of } \\
\text { Squares }\end{array}$ & $\begin{array}{l}\text { Mean } \\
\text { Squares }\end{array}$ & $\operatorname{Pr}>\mathrm{F}$ & $\begin{array}{l}\text { Variance } \\
\text { component }\end{array}$ & $\begin{array}{l}\% \text { var } \\
\text { due to } \\
\mathrm{cv}\end{array}$ \\
\hline \multicolumn{8}{|c|}{$\%$ Scalded fruit } \\
\hline \multirow[t]{2}{*}{1993} & Cultivar & 3 & 14488.7856 & 4829.5952 & 0.0001 & 960.6709 & 97.4 \\
\hline & Error & 16 & 419.8519 & 26.2407 & & 26.2407 & \\
\hline \multirow[t]{2}{*}{1994} & Cultivar & 3 & 19151.2164 & 6383.7388 & 0.0001 & 1575.8653 & 94.7 \\
\hline & Error & 14 & 445.0119 & 31.7866 & & -83.2535 & \\
\hline \multirow{3}{*}{1993} & & & & LOX & & & \\
\hline & Cultivar & 3 & 0.2775 & 0.0925 & 0.0001 & 0.0181 & 90.1 \\
\hline & Error & 16 & 0.0319 & 0.0020 & & 0.0020 & \\
\hline \multirow[t]{2}{*}{1994} & Cultivar & 3 & 0.1526 & 0.0509 & 0.0019 & 0.0083 & 52.9 \\
\hline & Error & 14 & 0.0847 & 0.0060 & & 0.0074 & \\
\hline
\end{tabular}




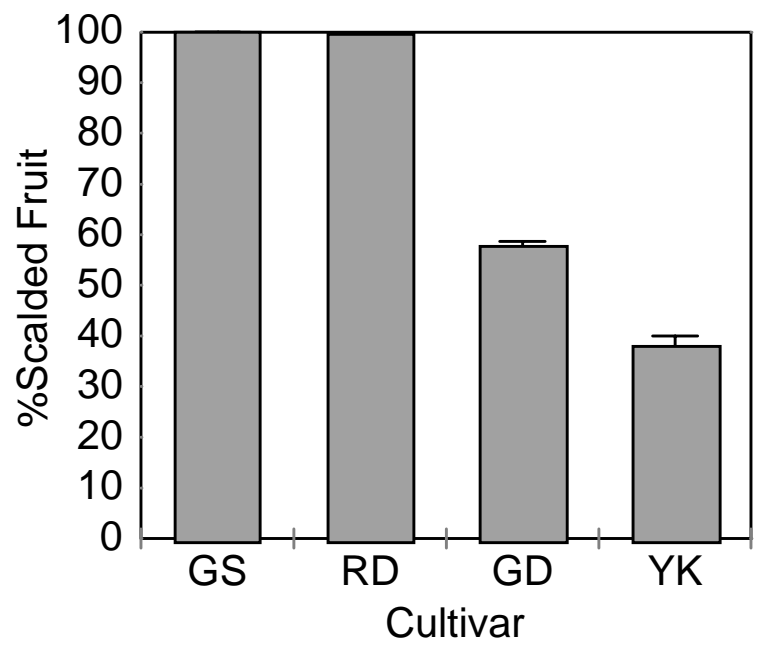

Figure 3. A comparison of 1993 harvest season \% scalded fruit for Granny Smith (GS), Red Delicious (RD), Golden Delicious (GD) and York (YK) apples. Cultivar differences in \% scalded fruit were significant $(\mathrm{P} \geq 0.0001)$. GS and RD \% scalded fruit were significantly higher than GD and $\mathrm{YK}(\mathrm{P} \leq 0.001)$ and GD was significantly higher than $\mathrm{YK}(\mathrm{P} \leq 0.001)$. Each bar represents the mean of three harvests (five replications each) for GS and of four harvests (five replications each) for RD, GD and $\mathrm{YK}+/$ - the standard error. 


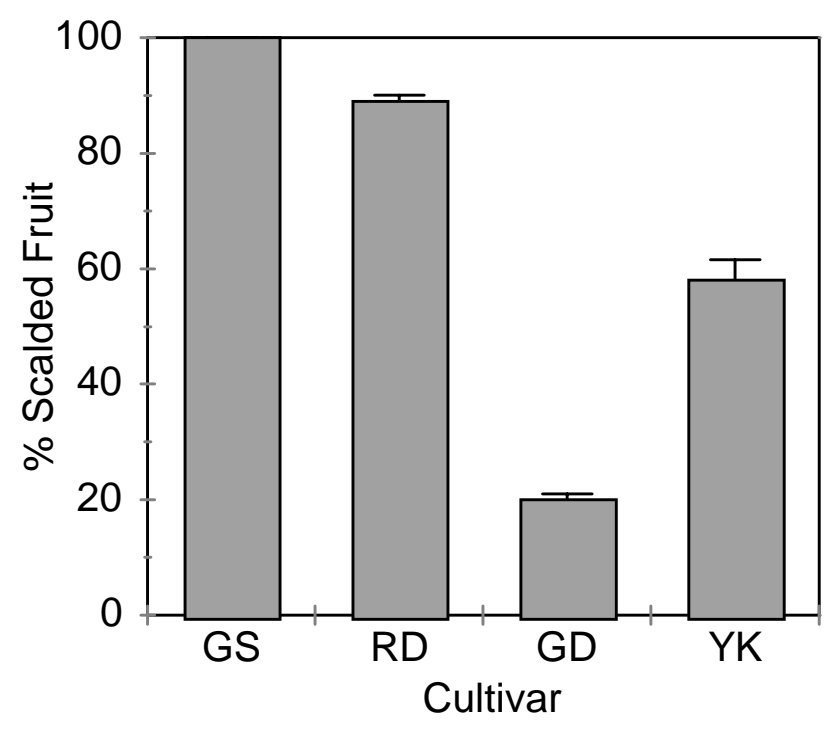

Figure 4. A comparison of 1994 harvest season \% scalded fruit for Granny Smith (GS), Red Delicious (RD), Golden Delicious (GD) and York (YK) apples. Cultivar differences in \% scalded fruit were significant $(\mathrm{P} \leq 0.0001)$ with $\mathrm{GS}$ and $\mathrm{RD}$ being significantly higher than GD and $\mathrm{YK}(\mathrm{P} \leq \mathrm{0.0001})$. Each bar represents the means of three harvests (five replications each) for GS, RD and GD, and of four harvests (three replications each) for YK +/- the standard error. 
Table 4. Orthogonal comparisons of $\%$ scalded fruit and lipoxygenase activity ${ }^{\mathrm{x}}$ (LOX) for Granny Smith (GS), Red Delicious (RD), Golden Delicious (GD) and York (YK) apples for the 1993 and for the 1994 harvest seasons.

\begin{tabular}{llll}
\hline Year & $\begin{array}{l}\text { Scald susceptibility } \\
\text { High vs low }\end{array}$ & \multicolumn{1}{c}{$\begin{array}{c}\text { Color } \\
\text { Red vs non-red }\end{array}$} & Interaction \\
& GS \& RD vs GD \& YK & RD \& YK vs GS \& GD & GS \& YK vs RD \& GD \\
\hline & & $\%$ Scalded Fruit & \\
1993 & $100 \%$ vs $48 \%^{* * * *}$ & $69 \%$ vs $79 \% * * *$ & $69 \%$ vs $79 \%^{* * *}$ \\
1994 & $95 \%$ vs $39 \%^{* * * *}$ & $74 \%$ vs $60 \%^{* * *}$ & $79 \%$ vs $5 \%^{* * * *}$ \\
& & \multicolumn{1}{c}{ LOX } & \\
1993 & 0.3230 vs $0.1075^{* * * *}$ & 0.2473 vs $0.1898^{* * *}$ & 0.1917 vs $0.2953^{* *}$ \\
1994 & 0.3881 vs $0.2055^{* * *}$ & 0.2506 vs $0.3429^{* *}$ & 0.2972 vs $0.2964^{\mathrm{NS}}$ \\
\hline
\end{tabular}

${ }^{\mathrm{x}} \mathrm{LOX}$ was measured as $\Delta \mathrm{A}_{234}$. One $\mathrm{A}_{234}$ unit was equivalent to $0.12 \mu$ mole of linoleic acid.

$\mathrm{NS}, *, * *, * * *, * * * *$ Nonsignificant or significant at $\mathrm{P} \leq 0.05,0.01,0.001,0.0001$ respectively. 
Table 5. Analysis of variates for the number of apples of each scald severity level ( $\mathrm{SA}=0, \mathrm{SB}=$ up to $10 \%, \mathrm{SC}=11$ to $50 \%$, SD = over 50\% visible scald) for Granny Smith (GS), Red Delicious (RD), Golden Delicious (GD) and York (YK) apples for the 1993 and for the 1994 harvest seasons.

\begin{tabular}{|c|c|c|c|c|c|}
\hline Severity & Source & $\mathrm{df}$ & $\begin{array}{l}\text { Sum of } \\
\text { Squares }\end{array}$ & $\begin{array}{l}\text { Mean } \\
\text { Squares }\end{array}$ & $\operatorname{Pr}>\mathrm{F}$ \\
\hline & & & 1993 & & \\
\hline SA & $\begin{array}{l}\text { Cultivar } \\
\text { Error }\end{array}$ & $\begin{array}{l}15 \\
44\end{array}$ & $\begin{array}{r}5352.4250 \\
772.5083\end{array}$ & $\begin{array}{r}386.8200 \\
17.5570\end{array}$ & 0.0001 \\
\hline SB & $\begin{array}{l}\text { Cultivar } \\
\text { Error }\end{array}$ & $\begin{array}{l}15 \\
44\end{array}$ & $\begin{array}{r}4220.5667 \\
302.9167\end{array}$ & $\begin{array}{r}281.3711 \\
6.8845\end{array}$ & 0.0001 \\
\hline $\mathrm{SC}$ & $\begin{array}{l}\text { Cultivar } \\
\text { Error }\end{array}$ & $\begin{array}{l}15 \\
44\end{array}$ & $\begin{array}{r}1215.9417 \\
784.5417\end{array}$ & $\begin{array}{l}81.0628 \\
17.8305\end{array}$ & 0.0001 \\
\hline SD & $\begin{array}{l}\text { Cultivar } \\
\text { Error }\end{array}$ & $\begin{array}{l}15 \\
44\end{array}$ & $\begin{array}{r}14596.2000 \\
1120.5500\end{array}$ & $\begin{array}{r}973.0800 \\
25.4670\end{array}$ & 0.0001 \\
\hline & & & 1994 & & \\
\hline SA & $\begin{array}{l}\text { Cultivar } \\
\text { Error }\end{array}$ & $\begin{array}{l}15 \\
38\end{array}$ & $\begin{array}{r}5071.1741 \\
645.8630\end{array}$ & $\begin{array}{r}338.0783 \\
16.9964\end{array}$ & 0.0001 \\
\hline SB & $\begin{array}{l}\text { Cultivar } \\
\text { Error }\end{array}$ & 15 & $\begin{array}{r}2252.0185 \\
158.5185\end{array}$ & $\begin{array}{r}150.1346 \\
13.6452\end{array}$ & 0.0001 \\
\hline $\mathrm{SC}$ & $\begin{array}{l}\text { Cultivar } \\
\text { Error }\end{array}$ & $\begin{array}{l}15 \\
38\end{array}$ & $\begin{array}{l}699.9593 \\
307.9111\end{array}$ & $\begin{array}{r}46.6640 \\
8.1029\end{array}$ & 0.0001 \\
\hline SD & $\begin{array}{l}\text { Cultivar } \\
\text { Error }\end{array}$ & $\begin{array}{l}15 \\
38\end{array}$ & $\begin{array}{r}4087.7704 \\
491.0630\end{array}$ & $\begin{array}{r}272.5180 \\
12.9227\end{array}$ & 0.0001 \\
\hline
\end{tabular}




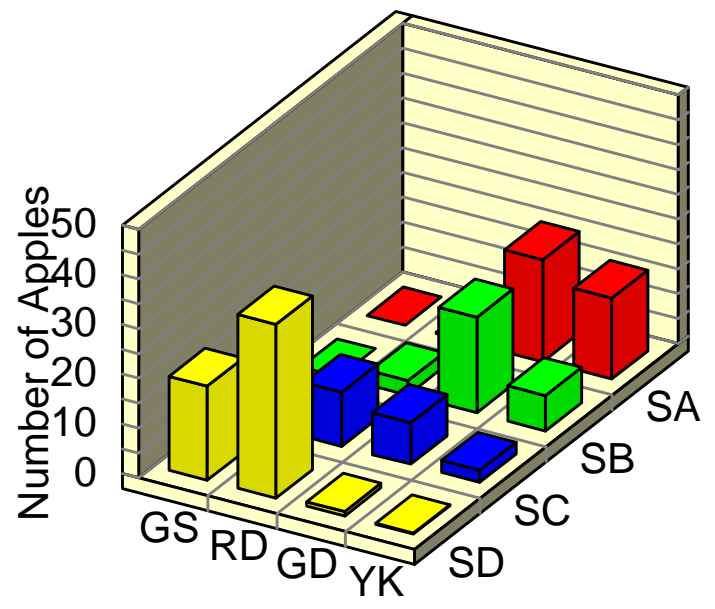

Cultivar

Figure 5. A comparison of the number of apples of each severity level ( $\mathrm{SA}=0, \mathrm{SB}=$ up to $10 \%$, $\mathrm{SC}=11$ to 50\%, and $\mathrm{SD}=$ over 50\% scald) for the 1993 harvest season for Granny Smith (GS), Red Delicious (RD), Golden Delicious (GD) and York (YK) apples. The cultivar differences in the numbers of SA, SB, SC and SD were significant ( $\mathrm{p} \geq 0.0001)$. Each bar represents the mean of three harvests (five replications each) for GS and of four harvests (five replications each) for $\mathrm{RD}, \mathrm{GD}$ and $\mathrm{YK}+/$ - the standard error. Note: GS SB=0. 


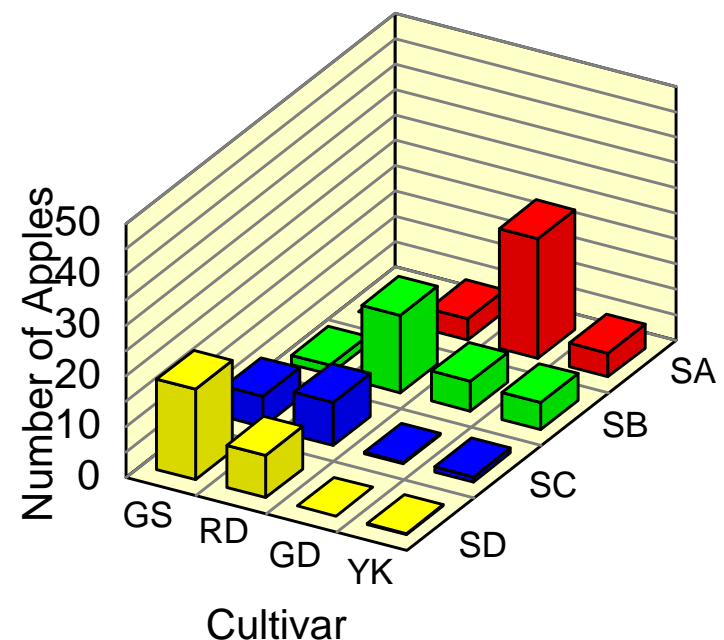

Figure 6. A comparison of the number of apples of each severity level ( $\mathrm{SA}=0, \mathrm{SB}=$ up to $10 \%$, $\mathrm{SC}=11$ to $50 \%$, and $\mathrm{SD}=$ over 50\% scald) for the 1994 harvest season for Granny Smith (GS), Red Delicious (RD), Golden Delicious (GD) and York (YK) apples. The cultivar differences in the numbers of SA, SB SC and SD apples were significant $(\mathrm{p} \geq 0.0001)$. Each bar represents the mean of three harvests (five replications each) for GS, RD and GD and of four harvests (three replications each) for $\mathrm{YK}+/$ - the standard error. Note: GS SA=0. 


\section{LOXO}

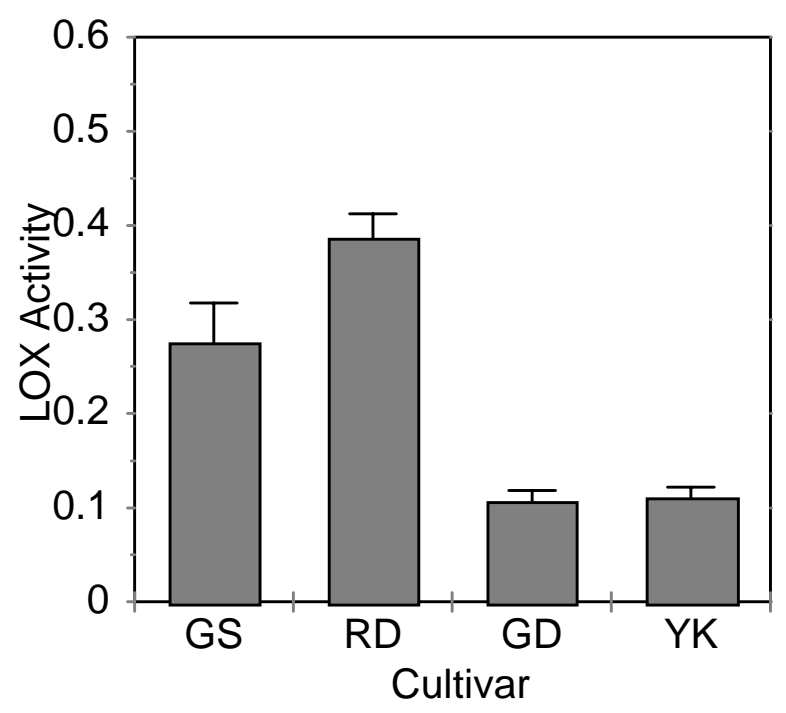

Figure 7. A comparison of the 1993 harvest season lipoxygenase activity (LOX) of Granny Smith (GS), Red Delicious (RD), Golden Delicious (GD) and York (YK) apple peel. Cultivar differences in LOX were significant $(\mathrm{P} \geq 0.0001)$. GS and RD had significantly higher LOX $(\mathrm{P} \leq 0.001)$ than GD and YK. LOX activity was measured as $\Delta \mathrm{A}_{234}$. One $\mathrm{A}_{234}$ unit was equavalent to the oxidation of $0.12 \mu$ mole of linoleic acid. Each bar represents the mean of three harvests (five replications each) for GS and of four harvests (five replications each) for RD, RD and YK +/- the standard error. 


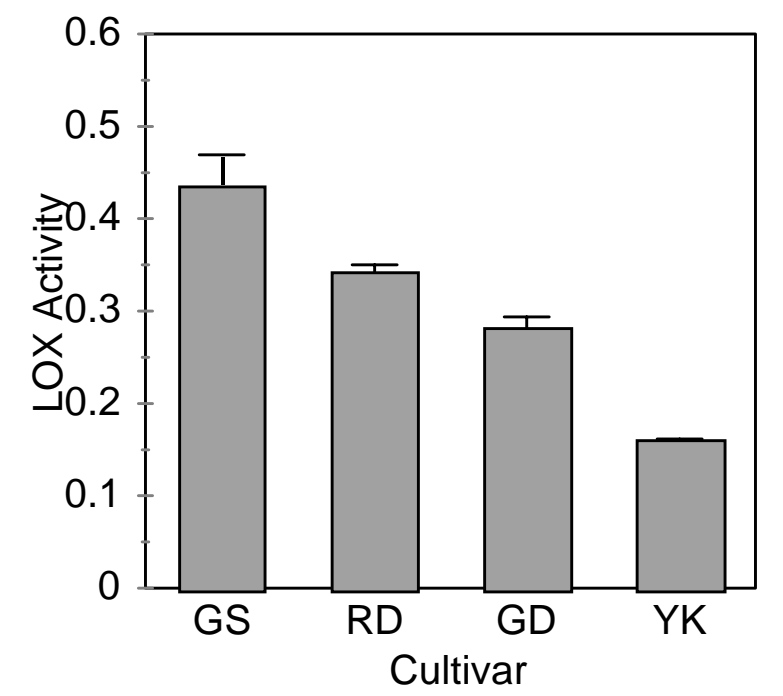

Figure 8. A comparison of the 1994 harvest season lipoxygenase activity at harvest (LOX) of Granny Smith (GS), Red delicious (RD), Golden Delicious (GD) and York (YK) apple peel. Cultivar difference in LOX0 was significant $(\mathrm{p} \geq 0.001)$. GS and RD were significantly higher than GD and $\mathrm{YK}(\mathrm{P} \leq 0.001)$. LOX activity was measured as $\Delta \mathrm{A}_{234}$. One $\mathrm{A}_{234}$ unit was equivalent to the oxidation of $0.12 \mu$ mole of linoleic acid. Each bar represents the mean of three harvests (five replications each) for GS, RD and GD and of four harvests (three replications each) for $\mathrm{YK}+/$ - the standard error. 


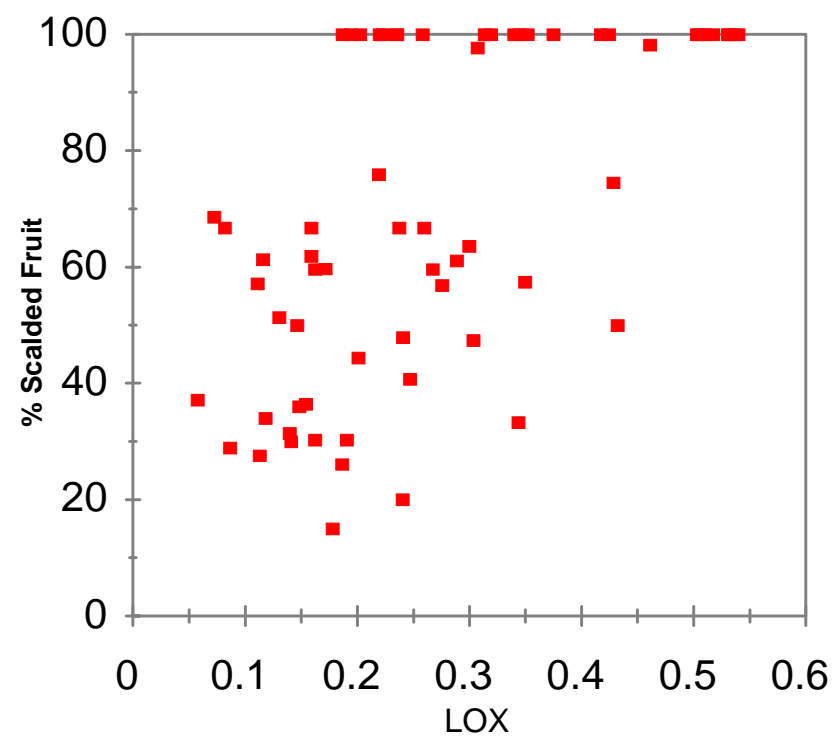

Figure 9. Combined data from Granny Smith, Red Delicious, Golden Delicious and York apples for the 1993 harvest year showing \% scalded fruit plotted against LOX activity. 
Table 6. Correlations between $\%$ scalded fruit and lipoxygenase activity ( $\mathrm{x}$ LOX) at harvest for Granny Smith (GS), Red Delicious (RD), Golden Delicious (GD) and York (YK) apples for the 1993 and for the 1994 harvest seasons.

\begin{tabular}{llll}
\hline Cultivar & Observations & ${ }^{\mathrm{y}}$ Pearson's Partial & ${ }^{\mathrm{Z}}$ Significance \\
& Correlation Coefficients &
\end{tabular}

\begin{tabular}{|c|c|c|c|}
\hline \multicolumn{4}{|c|}{1993} \\
\hline Combined & 75 & 0.6446 & $* * * *$ \\
\hline GS & 15 & 0.0000 & $\mathrm{a}$ \\
\hline $\mathrm{RD}$ & 20 & -0.143 & NS \\
\hline GD & 20 & 0.0529 & NS \\
\hline \multirow[t]{2}{*}{ YK } & 20 & 0.1058 & NS \\
\hline & & 1994 & \\
\hline Combined & 57 & 0.3992 & $* *$ \\
\hline GS & 15 & 0.0000 & $\mathrm{a}$ \\
\hline $\mathrm{RD}$ & 15 & 0.0078 & NS \\
\hline GD & 15 & 0.2333 & NS \\
\hline YK & 12 & 0.4142 & NS \\
\hline
\end{tabular}




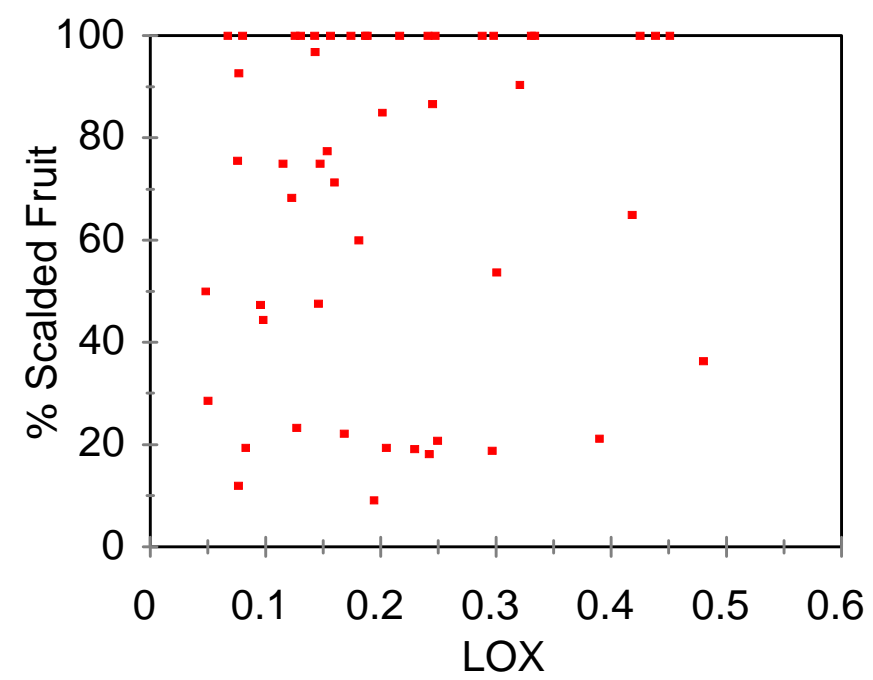

Figure 10. Combined data from Granny Smith, Red Delicious, Golden Delicious and York apples for the 1994 harvest year showing \% scalded fruit plotted against LOX activity. 


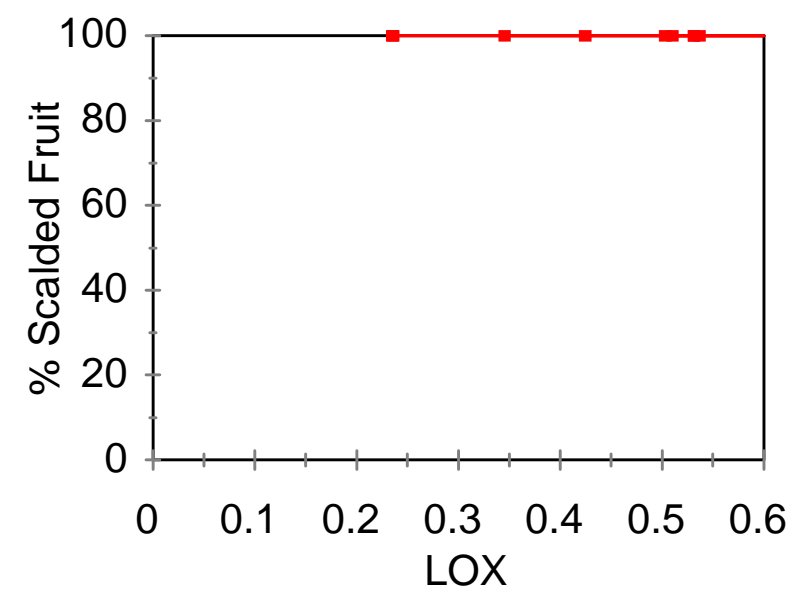

Figure 11. \% scalded fruit plotted against LOX activity for Granny Smith apples for the 1993 harvest year. 


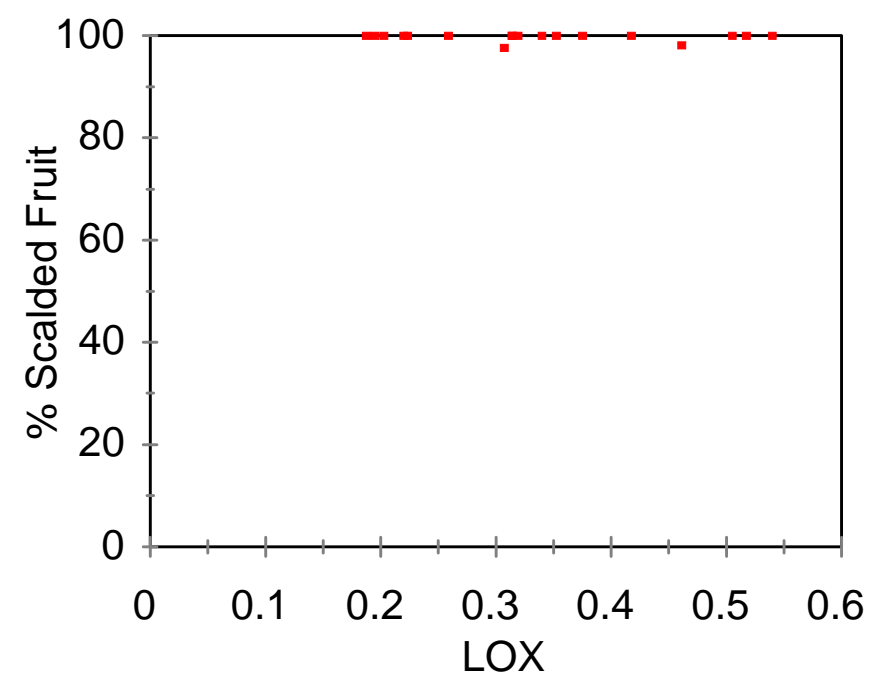

Figure 12. \% scalded fruit plotted against LOX activity for Red Delicious apples for the 1993 harvest year. 


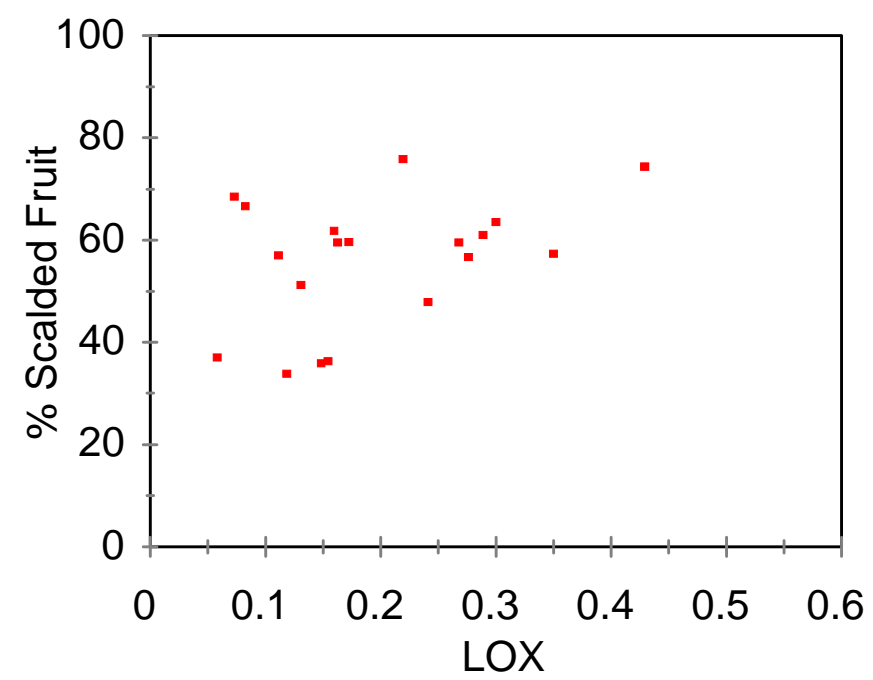

Figure 13. \% scalded fruit plotted against LOX activity for Golden Delicious apples for the 1993 harvest year. 


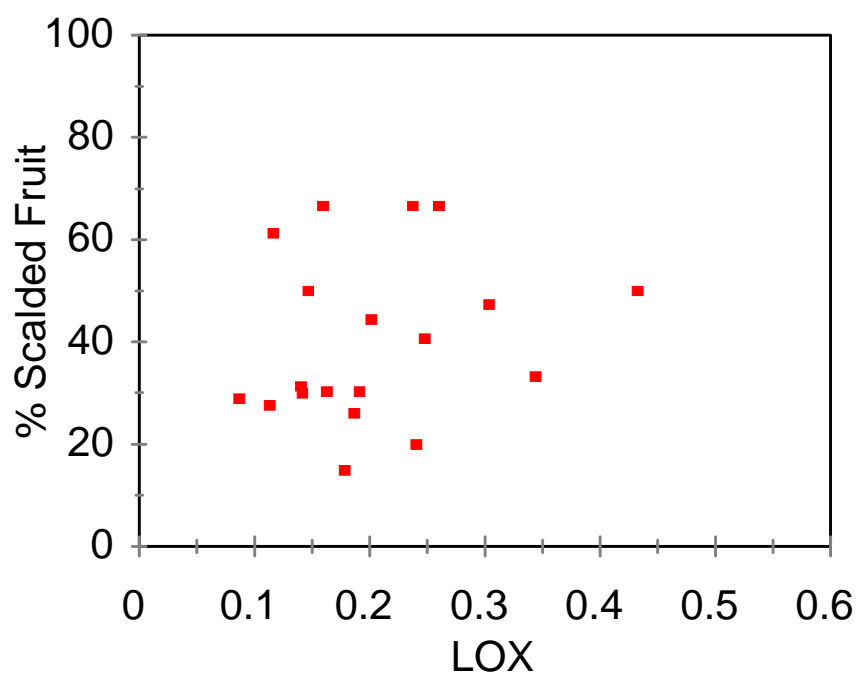

Figure 14. \% scalded fruit plotted against LOX activity for York apples for the 1993 harvest year 


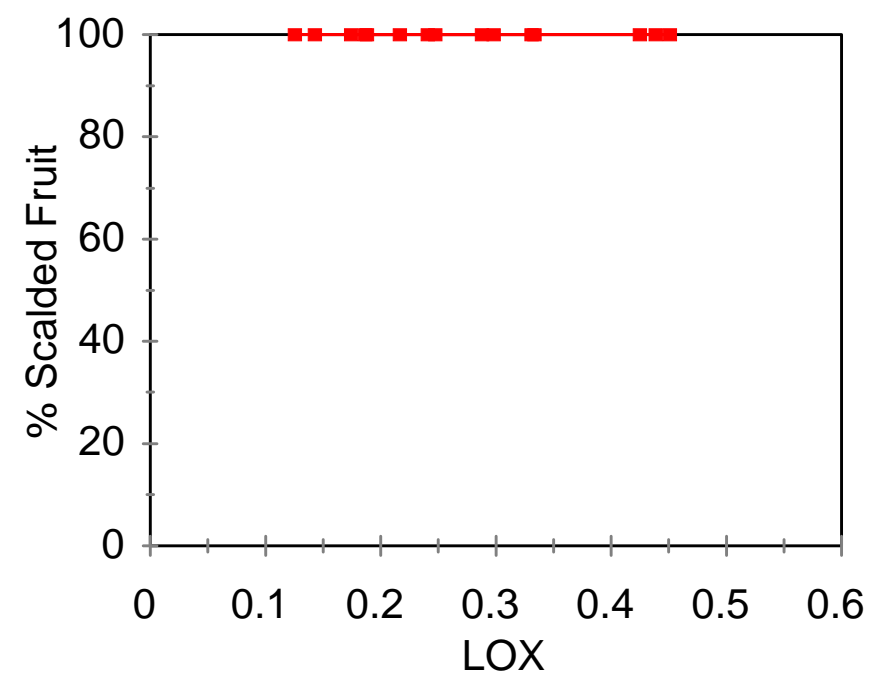

Figure 15. \% scalded fruit plotted against LOX activity for Granny Smith apples for the 1994 harvest year. 


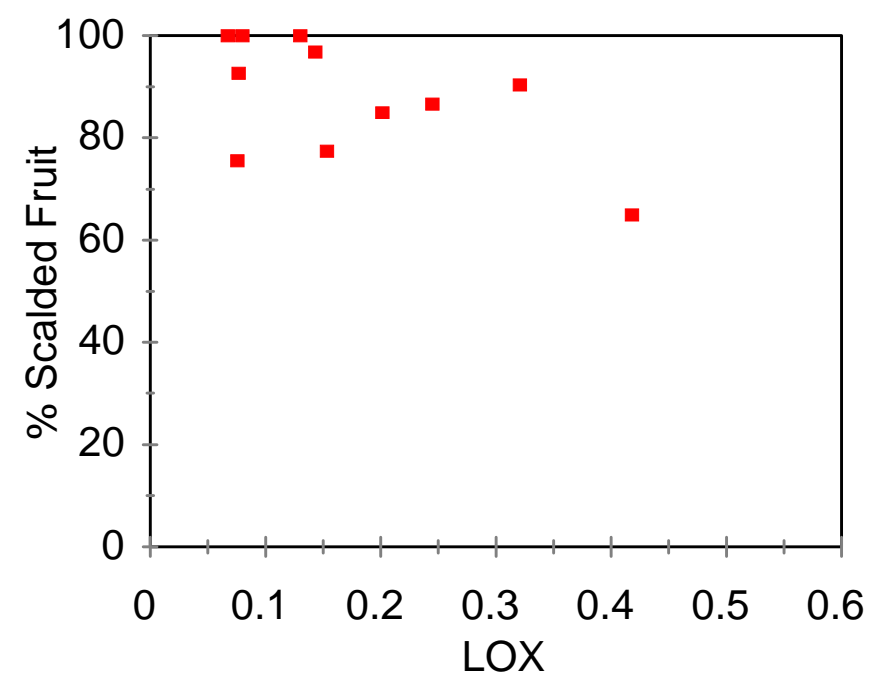

Figure 16. \% scalded fruit plotted against LOX activity for Red Delicious apples for the 1994 harvest year. 


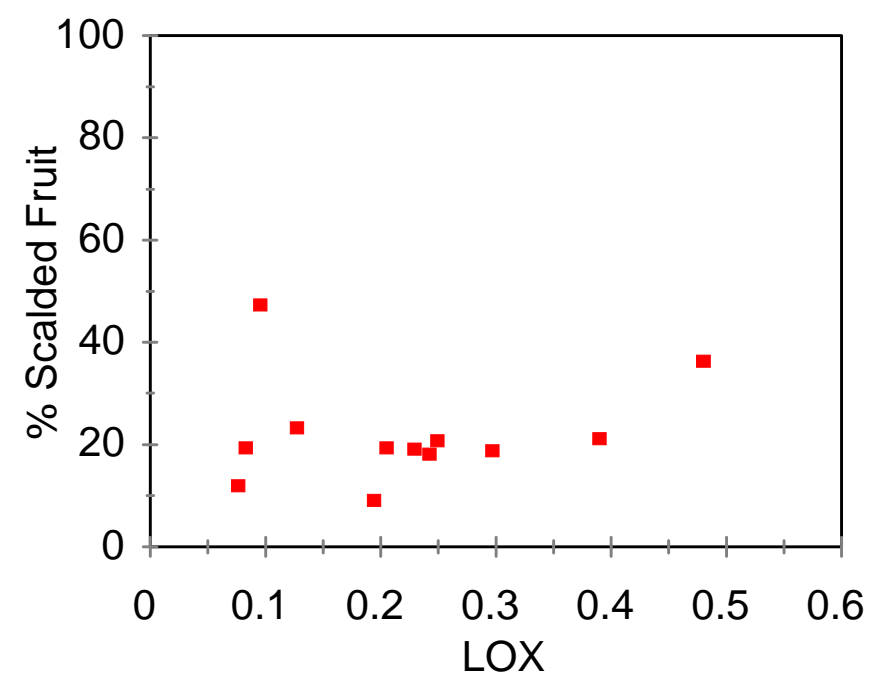

Figure 17. \% Scalded fruit plotted against LOX activity for Golden Delicious apples for the 1994 harvest year. 


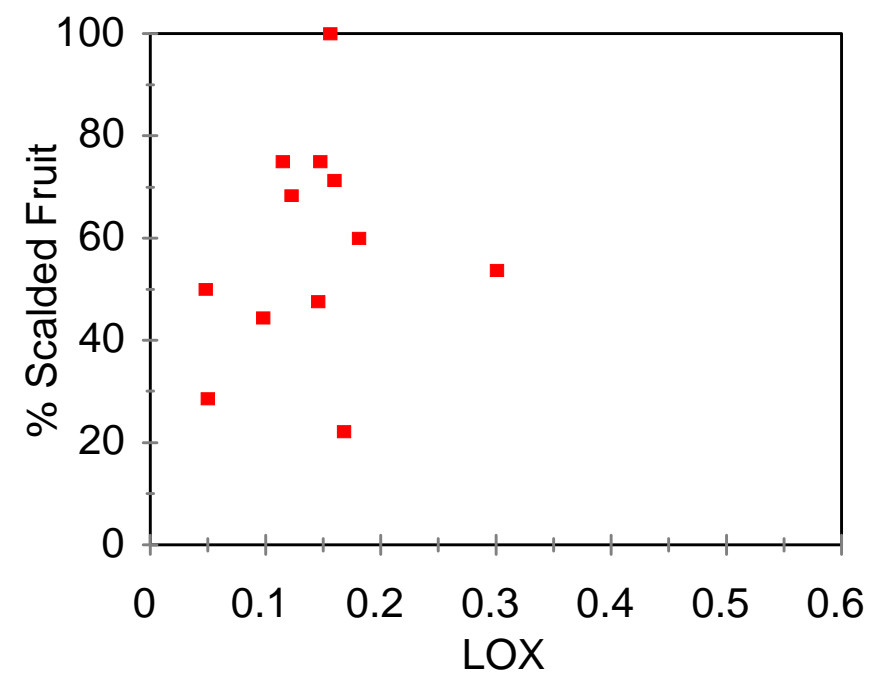

Figure 18. \% Scalded fruit plotted against LOX activity for York apples for the 1994 harvest year. 
Table 7. Variances of \% scalded fruit and LOX activity within cultivars for Granny Smith (GS), Red Delicious (RD), Golden Delicious (GD) and York (YK) apples for the 1993 and for the 1994 harvest years.

\begin{tabular}{llll} 
Cultivar & Observations & LOX & \% Scalded Fruit \\
\hline & & 1993 & \\
& & & \\
GS & 15 & 0.1490 & 16.9575 \\
RD & 20 & 0.1530 & 2060.6240 \\
GD & 20 & 0.0503 & 1411.1268 \\
YK & 20 & 0.0380 & \\
& & & \\
& & & \\
& & 1994 & 0 \\
GS & 15 & & 519.8520 \\
RD & 15 & 0.1028 & 890.1493 \\
GD & 15 & 0.1034 & 716.6333 \\
YK & 12 & 0.0372 & \\
\hline
\end{tabular}




\section{$\underline{\text { DISCUSSION }}$}

Due to increased restrictions by the United States Government involving the use of chemical scald inhibitors (D'Souza, 1991) identification of the gene(s) controlling scald has been sought (Du and Bramlage, 1994a, Shewfelt and Purvis, 1995). The economic effect of scald is that sale lots of fruit with $10 \%$, or greater, showing visible scald are excluded from the fresh fruit market, and must be sold for processing at approximately one third the price for fresh fruit (Ingle, 1997; U.S. Dept. of Agr., 1972). Reducing the $\%$ of scalded fruit below $10 \%$ of a sale lot by genetic means would increase the profit to the grower. It has been suggested that LOX has a role in scald production (Bain 1956, Ingle and D'Souza, 1989) since LOX has been shown to be active in senescence in a number of plants (Fobel et al., 1987; Hildebrand, 1989; Peary and Prince, 1990; Wardale and Lambert, 1980) and in the breakdown of lipids in plant cells (Hamberg and Gardner, 1992, Sembdner and Parthier, 1993).

The biosynthetic pathway from linolenic to jasmonic acid mediated by LOX has been demonstrated (Gundlach and Zenk, 1998). Jasmonic acid has been shown to stimulate the production of ethylene forming enzyme (Saniewski et al., 1987b; Koda, 1992). Increased ethylene production was associated with increased $\alpha$-farnesene production. Severity of scald has been shown to be proportional to the amount of $\alpha$-farnesene in the skin of affected apples (Huelin and Coggiola, 1968b; Anet 1970; Ingle and D’Souza, 1989; Figure 19; Watkins et al., 1993).

There was a significant cultivar difference in \% scalded fruit $(\mathrm{P} \leq 0.0001)$ for both the 1993 and the 1994 harvest seasons. The two high scald susceptibility cultivars, GS and RD, had significantly higher $\%$ scalded fruit than the two low scald susceptibility cultivars, GD and YK for 
both years (Figure 3, Figure 4 and Table 4). Ninety- five \% or more of the variance in the amount of scalded fruit was due to cultivar (Table 3). A comparison of the number of apples at each severity level of scald, SA, SB, SC and SD, for the 1993 harvest season showed significant difference $(\mathrm{P} \leq$ 0.0001) between the four test cultivars for SA, SB, SC and SD (Table 5). This is consistent with the expected cultivar difference (Ingle and D'Souza, 1989; Meigh, 1970; Smock, 1961). For the 1993 and the 1994 harvest season, all four test cultivars had over 10\% scalded fruit after 150 days RS + 7 days at RT and would have been excluded from the fresh fruit market.

There was a significant cultivar difference in LOX for the 1993 harvest season $(\mathrm{P} \leq 0.0001)$ (Table 3). The two high scald susceptibility cultivars had significantly higher LOX activity than the two low scald susceptibility cultivars. RD had significantly higher LOX activity than GS. GD and YK had similar levels of activity (Figure 7 and Table 3). The two cultivars that had the higher $\%$ scalded fruit (see Figure 3) also exhibited the higher LOX activity. Also, the two high LOX - high $\%$ scalded fruit cultivars had more apples in the SC and SD categories than the two low LOX - low $\%$ scalded fruit cultivars. RD which had the highest LOX also had the highest number of the most severely scalded fruit (Figure 5 and Table 5). LOX at harvest was also significantly different between the cultivars tested for the 1994 harvest season $(\mathrm{P} \leq 0.01)$. Again the two high scald susceptibility cultivars had significantly greater LOX activity than the two low scald susceptibility cultivars (Figure 8 and Table 3). Again the two higher Lox activity cultivars had the higher $\%$ scalded fruit and the greater numbers of more severely scalded fruit (Figure 6 and Table 5).

The correlation between \% scalded fruit and LOX for the combined cultivars in 1993 and 1994 were highly significant $(\mathrm{P} \leq 0.0001)$ (Table 6 and Figure 9). There is a pattern of higher $\%$ scalded fruit with increasing LOX. However, all of the $100 \%$ scalded fruit occurred in GS and RD. 
These two cultivars had little or no variation in \% scalded fruit(Table 7). GS had no variation in \% scalded fruit and therefore no correlation. RD had a negative correlation $(-0.1432)$ because the two replicates with less than 100\% scalded fruit had higher LOX than some of the 100\% scalded fruit replicates. GS and RD had similar variance in LOX which was about three times the LOX variance in GD and YK. GD and YK LOX variances were similar to each other. Therefore the correlation in the combined cultivars is due to the distributions of the GD and YK LOX values. Although there was greater variation in LOX in the two high scald susceptible cultivars, there was little variation in the \% scalded fruit and therefore little or no correlation. The correlation in RD was negative because there were only two replications with less than $100 \%$ scalded fruit and both had higher LOX than some of the $100 \%$ scalded fruit replications(Figure 12). Both GD and YK had a range of values for both \% scalded fruit and for LOX with a pattern of higher \% scald-higher LOX and low $\%$ scald-low LOX occurring together (Figures 13 and 14).

The correlation between \% scalded fruit and LOX for the combined cultivars for 1994 (0.3992) was significant $(\mathrm{P} \leq 0.001)$ (Table 6) with the low LOX occurring with low scald but high LOX replicates showing a range of values for $\%$ scalded fruit. There was no variance in $\%$ scalded fruit for 1994 GS and the other three cultivar had similar variances. RD had about three times the variance in LOX as GD and YK and a and a very low correlation between LOX and \% scald since the \% scald values were all above $90 \%$. The 1994 GD and YK had similar variances for both \% scalded fruit and for LOX. Both cultivars had the highest $\%$ scalded fruit exhibiting the middle range of LOX. For both GD and YK the lowest \% scalded fruit had the lowest LOX. For GD the highest scalded fruit also had the highest LOX. The YK highest LOX had a middle range value for $\%$ scalded fruit and the highest $\%$ scalded fruit had a middle range of LOX contributing to the low 
correlation (Figures 14 and 14).

The trees for each cultivar on this study were propagated from cuttings and are considered to be genetically the same (Ingle, 1997). Variances within a cultivar are considered to be due to environment (Table 7).

The low correlation between LOX activity and the \% scalded fruit indicates that LOX is not the cause of scald. Since the two cultivars (GS and RD) with high \% scalded fruit had high LOX activity and the two cultivars (GD and YK) with low \% scalded fruit had low LOX activity it is probable that the cause of high LOX is the cause of high scald.

Apple peel homogenate had a $\mathrm{pH}$ range of 5.0 to 6.8. Apple LOX had a $\mathrm{pH}$ response curve showing $90 \%$ of activity occurring between pH 5.1 to 6.2 with the optimum at 6.0 (Kim, 1969). Eighty-nine $\%$ of the apple peel homogenates were within the $90 \%$ activity range.

Gas chromatography / mass spectroscopy (GC / MS) showed the presence of three (and probably a fourth) positional isomers of Jasmonic acid (Smith, 1996). These indicate three (probably four) LOX pathways (Fukuchi-Mizutani et al.,1995; Sembdner and Parthie,r 1993). This was consistent with the number of LOXs reported in other plant species. Four distinct LOXs have been

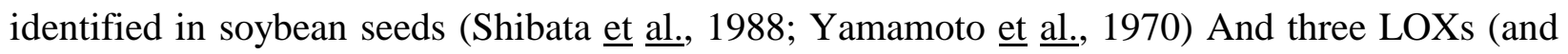
probably a fourth) have been identified in the tomato (Ferrie et al., 1994). Purification and sequencing of these four LOXs may show one or more of the isomers present in high concentrations in cultivars with high scald susceptibility but missing or present in low concentrations in low scald susceptible cultivars. Also, the LOX(s) most active in apple peel may recover activity at a lower temperature than the other enzymes in the apple peel, thus allowing scald damage to occur before the resumption of normal cell activity 
Although the correlation between LOX activity at harvest and the \% scalded fruit after 150 days RS + 7 day at RT is not useful as a predictor of scald severity, cultivars with higher LOX activity did have higher $\%$ of scalded fruit and higher numbers of severely scalded fruit in the four cultivars used in this study. Since over $50 \%$ of the variance in LOX activity and in \% of scalded fruit was due to cultivar, studying additional cultivars may show the same association between high LOX at harvest and high $\%$ scalded fruit and severity of scald. An economic study may then be done to determine if chemical treatments of low LOX cultivars is cost effective. Low LOX cultivars may be within acceptable limits of scald for the fresh fruit market with no or reduced treatment. The Bradford protein assay and the LOX assay require a spectrophotometer, readily available chemicals and can be done in one hour. A LOX activity scale could be developed to indicate use or concentration of chemical treatments to prevent superficial scald and additional cultivars or harvest lots of fruit could be easily tested. 


\section{Linoleic Acid $\rightarrow$ Linolenic Acid \\ $\downarrow-\downarrow$ \\ Lipoxygenase \\ $\downarrow$ \\ DH-JA JA \\ $\downarrow$ \\ Increased Ethylene Production \\ $\downarrow$ \\ Increased $\alpha$-farnesene Production}

Figure 19. Lipoxygenase activity pathway to increased $\alpha$-farnesene production (Gundlach and Zenk, 1998; Huelin and Murray, 1966; Koda, 1992; Watkins et al., 1993; Yang, 1987). 


\section{$\underline{\text { LITERATURE CITED }}$}

Ackermann, J., M. Fischer, and R. Amado. (1992). Changes in sugars, acids, and amino acids during ripening and storage of apples (cv. Glockenapfel). J. Agr. Food Chem., 1992, 40, 1131-1134.

Anet, E.F.L.J. (1969). Autoxidation of $\alpha$-farnesene. Aust. J. Chem., 22, 2403-2410.

Anet, E. F. L. J. (1970). Synthesis of (E, Z)- $\alpha$-, and (Z)- $\beta$-farnesene. Aust. J. Chem., 23, 21012108.

Anet, E.F.L.J. (1972). Superficial scald, a functional disorder of stored apples. J. Sci. Fd. Agr., 1972, 23, 763-769.

Bain, J.M. (1956) A histological study of the development of superficial scald in Granny Smith apples. J. Hort. Sci., 234-238.

Barden, C.L., and W.J. Bramlage. (1994). Accumulation of antioxidants in apple peel as related to preharvest factors and superficial scald susceptibility of the fruit. J. Amer. Soc. Hort. Sci. 119: 264-269.

Bowsher, C.G., B.J.M. Ferrie, S. Grosch, J.Todd, J.E. Thompson, and S.J. Rothsteen. (1992). 
Purification and partial characterization of a membrane- associated lipoxygenase in tomato fruit. Plant Physiol., 100: 1802-1807.

Bradford, M.M. (1976). A rapid and sensitive method for the quantitation of microgram quantities of protein utilizing the principle of protein dye binding. Anal. Bioch., 72: 248254.

Chen, P.M., K.L. Olsen and M. Meheriuk. (1985). Effect of low-oxygen atmosphere on storage scald and quality preservation of 'Delicious' apples. J. Amer. Soc. Hort., 110:16-20.

Christopher, J.P., E.K. Pistorius and B. Axelrod. (1972). Isolation of a third isozyme of soybean lipoxygenase. Biochim. Biophys. Acta, 284:54-62.

Dowdy, S. and S. Wearden. (1983). "Statistics for Research.” John Wiley \& Sons, New York.

Du, Z. and W.J. Bramlage. (1994a). Superoxide dismutase activities in senescing apple fruit (Malus domestica Borkh. ). Journal of Food Science, 59: 581-584.

Du, Z., and W.J. Bramlage. (1994b). Roles of ethylene in the development of superficial scald in 'Cortland' apples. J.Amer. Soc. Hort. Sci., 119: 516-523.

Du, Z., and W.J.Bramlage. (1995). Peroxodative activity of apple peel in relation to 
development of poststorage disorders. HortScience, 30: 205-209.

D’Souza, M.(1991). Investigation into the physiology and control if superficial scald of apples. Ph. D. Dissertation. West Virginia University, Morgantown, W.V.

Fargher, J., N.A.Smith. (1995). Evidence of cold shock sensitivity in brewing yeast strains. Proceedings of the European Brewery Convention, Brussels, 345-352.

Ferrie, B.J., N. Beaudoin, W. Borkhart, C.G. Bowsher, and S.J. Rothsteen. (1994). The cloning of two tomato lipoxygenase genes and their differential expressions during fruit ripening. Plant Physiol., 106: 109-118.

Feys, M.,W. Naesens, P. Tobback, and E. Maes. (1980). Lipoxygenase activity in apples in relation to storage and physiological disorders. Phytochemistry, 19: 1009-1011.

Fobel, M., D.V. Lynch, and J.E. Thompson. (1987). Membrane deterioration in senescing carnation flowers. Plant Physiol., 85: 204-211.

Fukuchi-Mizutani, M., K. Savin, E. Cornish, Y. Tanaka, T. Ashikara, T. Kasumi and N. Marata. (1995). Senescence-induced expression of $\Delta 9$ desaturase in rose petals. Plant Mol. Biol., 29: 627-635.

Ganthovorn,C. and J.R. Powers. (1989). Partial purification and characterization of asparagus 
lipoxygenase. Journal of Food Science, 54: 371-373.

Gundlach, H., and M.H. Zenk. (1998). Biological and Biosynthesis of pentacyclic oxylipins: the linoleic acid pathway. Phytochemistry, 47: 527-537.

Haller, M. H. and S. Smith. (1950). Evaluation of indixes of maturity of apples. USDA Tech. Bull. 1003.

Hamberg, M. and H. W. Gardner. (1992). Oxylipin pathway to jasmonates: biochemistry and biological significance. Biochem. Biophys. Acta, 1165, 1-18.

Hildebrand, D.F., T. R. Hamelton-Kemp, C.S. Legg, and G. Bookjans. (1988). Plant lipoxygenases: occurrence, Properties and possible functions. Current Topics in Plant Biochemistry and Physiology, 7: 201-219.

Hildbrand, D.F. (1989). Lipoxygenases. Physiologia Plantarum,76: 249-253.

Hudak, K., K. Yao, and J.E. Thompson. (1995). Release of fluorescent peroxidized lipids from membranes in senescing tissue by blebbing of lipid-protein particles. Hortscience, 30: 209-213.

Huelin, F.E. and K.E. Murray. (1966). $\alpha$-farnesene in the natural coating of apples. Nature, 
210:1260-1261.

Huelin, F.E. and I.M. Coggiola. (1968). Effect of variety, maturity, oiled wraps and diphenylamine on the concentration of $\alpha$-farnesene in the fruit. J. Sci. Fd. Agr., 19: 297-301.

Huelin, F.E. and I.M. Coggiola. (1970). Superficial scald, a functional disorder of stored apples. J. Sci. Fd. Agr., 21:44-48.

Hulme, A.C. (1970). In "The Biochemistry of Fruits and Their products." Vol.1. Academic Press, New York.

Ingle, M. and M. D’Souza. (1989). Physiology and control of superficial scald of apples: a review. Horticulture, 24: 28-31.

Ingle, M. (1997). Personal communication May 21, 1997.

Kader, A.A., and M.A. Stevens, M. Allenright-Holten, L.L. Morris, and M. Algazi. (1977). Effect of fruit ripeness when picked on flavor and composition in fresh market tomatoes. J. Amer. Soc. Hort. Sci., 102: 724-731.

Kanervo, E., Y.Tasaka, N. Murata, and E.Aro. (1997). Membrane lipid unsaturation modulates 
processing of the photosystem II reactoin-center protein D1 at low temperatures. Plant Physiol., 114:841-849.

Kim, I. and W. Grosch. (1979). Partial purification of a lipoxygenase from apples. J. Agr. Food Chem. ,27: 243-246.

Koch, R.B., B. Stern and C.G. Ferrari. (1958). Linoleic acid and trilinolein as substrates for soybean lipoxidase(s). Archives of Bioch. Biophys., 78: 165-179.

Koda, Y. (1992). The role of jasmonic acid related compounds in the regulation of plant development. Int. Rev. Cytology, 135:155-199.

Kristie, D., and J.E. Thompson. (1989). Inhibition of lipoxygenase activity: a cautionary note. Phytochemistry, 28; 2577-2581.

Littell, R.C. (1989). Statistical analysis of experiments with repeated measurements. HortScience 24:37-40.

Little, C.R., H.J. Taylor and I.D. Peggie. (1980). Multiformulation dips for controlling storage disorders of apples and pears. II. assessing scald inhibitors, Scientia Hortic., 13: 315321. 
Lynch, D.V., S. Sridhara, and J.E. Thompson. 1985. Lipoxygenase-generated hydroperoxides account for the non-physiological features of ethylene formation from 1-aminocyclopropane1-carboxylic acid by microsomal membranes of carnations. Planta, 164; 121-125.

Meigh, D.F. (1970). In “The Biochemistry of Fruits and Their Products.” Vol.1. Academic Press, New York.

Meigh, D.F. and I.M. Coggiola. (1970). Superficial scald, a functional disorder of stored apples. J. Sci. Fd. Agr. ,21:44-48.

Miegh, D.F. and A.C. Hulme. (1965). Fatty acid metabolism in the apple fruit during the respiration climacteric. Phytochemistry, 4: 863-871.

Meigh, D.F. and J. Reynolds. (1969). Effect of low concentrations of oxygen on the production of ethylene and on other ripening changes in apple fruit. J. Sci. Fd. Agr., 20: 225-228.

Paliyanth, G., D.V. Lynch, and J.E. Thompson. (1987). Regulation of membrane phospholipid catabolism in senescing carnation flowers. Physiologia Plantarium, 71: 503511.

Peary, J.S. and T.A. Prince. (1990). Floral lipoxygenase activity during senescence and inhibition by phenidone. J. Amer. Soc. Hort. Sci., 115: 455-457. 
Peterman, T.K. and J.N. Siedow. (1985). Behavior of lipoxygenase during establishment, senescence, and rejuvenation of soybean cotyledons. Plant Physiol., 78: 690-695.

Pierce Handbook and General Catalogue. 1989, 170.

Rhodes, M.J.C. (1970). In "The Biochemistry of Fruits and Their Products." Vol. I. Academic Press, New York.

Sanieweski, M., J. Czapski, and J. Nowacki. (1987a). Relationship between stimulating effect of methyl jasmonate on ethylene production and 1-aminocyclopropane-1-carboxylic acid content in tomatoes. Biol. Planta, 29:17-21.

Saniewski,M., J. Nowacki, and J. Czapski. (1987b). The effect of methyl jasmonate on ethylene production and ethylene-forming enzyme activity in tomatoes. J. Plant Physiol.,129:175180.

SAS Institute Inc., SAS / STAT® User's Guide Version 6, Fourth Edition Volumes 1 and 2, Cary, NC: SAS Institute, 1990.

Sembdner, G., and B. Parthier. (1993). The biochemistry and the physiological and molecular actions of jasmonates. Annu. Rev. Plant Physiol. Plant Mol. Biol., 1993, 44: 569-589. 
Shibata, D., J. Steczko, J.E. Dixon, P.C. Andrews, M. Hermodson, and B. Axelrod. (1988). Primary structure of soybean lipoxygenase L-2. Journal of Biological Chemistry, 263: 6816-6821.

Shewfelt, R.L. And A.C. Purvis. (1995). Toward a comprehensive model for lipid peroxidation in plant tissue disorders, Hortscience. Vol. 30: 213-218.

Siegelman, H.W. , and H.A. Schomer. (1953). Effect of scald on apple skin respiration. Pl. Physiol., 29: 429-431.

Sigma Catalogue, 1995. P662.

Smock, R.M. (1961). Methods of scald control on the apple. N.Y.(Cornell) Agr. Expt. Sta. Bul. 970.

Smith, Robert, M.S.E.E., gas Chromatograph/ Mass Spectrphotometer Technician, Health Sciences, West Virginia University, Morgantown, West Virginia.

Todd, J.F., G. Paliyanth, and J.E. Thompson. (1990). Characteristics of a membraneassociated lipoxygenase in tomato fruit. Plant Physiol. , 94: 1225-1232.

Townsend, E. (1998). Personal communication November 16,1998. 
Ueda, J. And J. Kato. (1980). Isolation and identification of a senescence-promoting substance from wormwood (Artemisia absinthium L.). Plant Physoil. ,66: 246-249.

U.S. Department of Agriculture, Agriculture Marketing Service. 1972. United States standards for the grades of apples. Amended 1 Oct. 1966 and 1 July 1972. U.S. Dept Agr., Washington, D.C.

Vick, B.A., and D.C. Zimmerman. (1984). Biosynthesis of jasmonic acid by several plant species. Plant Physiol., 75:458-461.

Wardale, D.A. and E.A. Lambert. (1980). Characteristics of membrane-associated lipoxygenase in tomato fruit. Plant Physiol., 94: 1225-1232.

Watkins, C.B., C.L. Barden and W. J. Bramlage. (1993). Relationship between alphafarnesene, ethylene production and superficial scald development of apples. Acta Hort., $343,155-160$.

Watkins, C.B., W.J. Bramlage, and B.A. Cregoe. (1995). Superficial scald of 'Granny Smith' apples is expressed as a typical chilling injury. J. Amer. Soc. Hort. Sci., 120:88-94.

Whitaker, B.D. (1994). Lipid changes in mature-green tomatoes during ripening, during chilling, and after rewarming subsequent to chilling. J. Amer. Soc. Hort. Sci., 119:994- 
999.

Wilkenson, B.G. (1970). In “ The Biochemistry of Fruits and Their Products." Vol.I, Academic Press, New York.

Yamamoto, A.,K. Yasamoto and H. Mitsuda. (1970). Isolation of lipoxygenase isozymes and comparison of their properties. Agr. Biol. Chem., Vol. 34: 1169-1177.

Yang, S.F. (1987). Regulation of biosynthesis and action of ethylene. Acta Hortic., 201:53-59. 


\section{Appendix 1}

Coomassie Brilliant Blue Reagent

One hundred mg Coomassie brilliant blue G-250 (Bio-Rad Laboratories) was dissolved in $50 \mathrm{ml} \mathrm{95 \%} \mathrm{ethanol} \mathrm{to} \mathrm{which} 100 \mathrm{ml}$ of $85 \%$ phosphoric acid (Baker) had been added. This solution was diluted with deionized distilled water (ddH2O) to yield $1 \mathrm{~L}$. The solution was filtered through Whatman No.1 filter paper and stored at 4 C (Bradford, 1976).

\section{Buffer A}

One hundred mM 3-(N-morpholino) propanesulfonic acid (MOPS) (Sigma), $10 \mathrm{mM}$ Ethylene glycol-bis-(B-aminoethyl ether)-N,N,N',N'-tetraacetic acid (EGTA) (Sigma), 7 \% RNAase-free sucrose (Schwarz/Mann Inc.), and 2mM dithiothreitol (DTT) (Sigma) were added to $600 \mathrm{ml}$ of ddH2O. The $\mathrm{pH}$ to was adjusted to 7.6 with $6 \mathrm{~N}$ Sodium Hydroxide $(\mathrm{NaOH})$ (Fisher). Five $\mathrm{ml}$ of Tween 20 (Fisher) was added and the solution was diluted to $1 \mathrm{~L}$ with ddH2O. $\mathrm{pH}$ of final dilution was adjusted to 7.6 with $6.0 \mathrm{~N} \mathrm{NaOH}$ if necessary. The solution was sterilizd by filtration through a $0.2-\mathrm{m}$ pore size cellulose acetate membrane (Nalgene) and stored

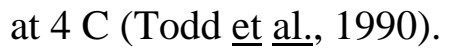




\section{Buffer B}

Fifty $\mathrm{mM}$ MOPS were added to $600 \mathrm{ml} \mathrm{ddH2O}$ and the $\mathrm{pH}$ was adjusted to 7.0 with $6 \mathrm{~N}$ $\mathrm{NaOH}$. The solution was diluted to $1 \mathrm{~L}$ with ddH2O. $\mathrm{pH}$ was adjusted to $\mathrm{pH} 7.0$ with $6 \mathrm{~N} \mathrm{NaOH}$ if necessary. Solution was sterilized by filtration through a 0.2 -m pore size cellulose acetate membrane (Nalgene). Buffer was stored at 4C and brought to room temperature before use (Todd, 1990).

\section{Linoleic Acid Substrate for LOX Activity Evaluation}

One hundred $\mu \mathrm{l}$ of Tween 20 in $20 \mathrm{ml}$ of Buffer B were placed in a capped polypropylene centrifuge tube. Headspace was flushed with N 2 for 30 seconds. Twenty $\mu 1$ linoleic acid (Sigma) were added and the headspace was flushed again with N2 for 30 seconds. The cap was secured. The substrate was vortexed and allowed to incubate at room temperature for 10 minutes. Substrate was used within three hours after preparation (Todd $\underline{\text { et }} \underline{\text { al., }}$ 1990). 